Reza Daryaei, Montaser Bakroon, Daniel Aubram, Frank Rackwitz

\title{
Numerical evaluation of the soil behavior during pipe-pile installation using impact and vibratory driving in sand
}

Journal article | Accepted manuscript (Postprint)

This version is available at https://doi.org/10.14279/depositonce-10472

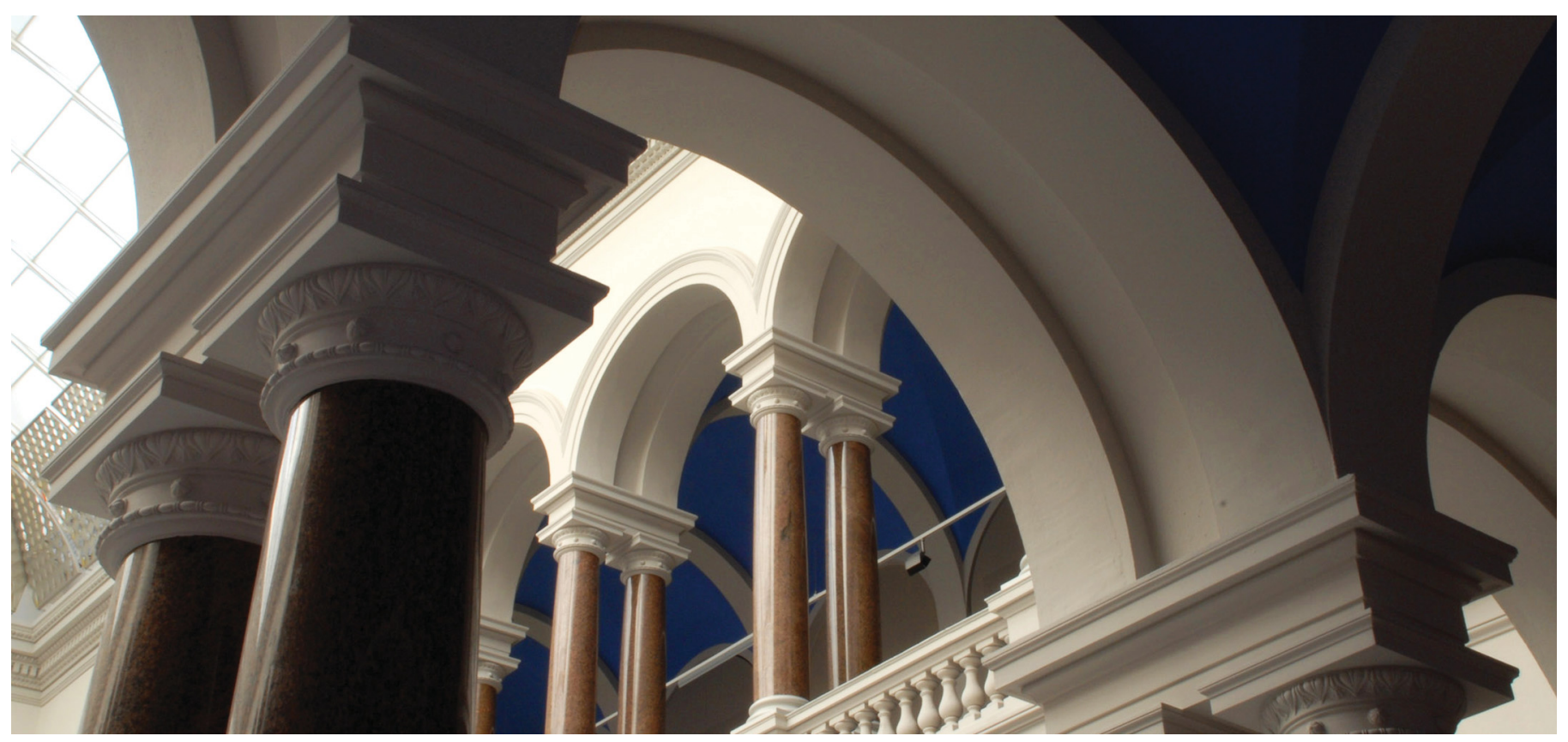

Daryaei, R., Bakroon, M., Aubram, D., \& Rackwitz, F. (2020). Numerical evaluation of the soil behavior during pipe-pile installation using impact and vibratory driving in sand. Soil Dynamics and Earthquake Engineering, 134, 106177. https://doi.org/10.1016/j.soildyn.2020.106177 
Accepted manuscript of: Daryaei, R., Bakroon, M., Aubram, D., \& Rackwitz, F. (2020). Numerical evaluation of the soil behavior during pipe-pile installation using impact and vibratory driving in sand. Soil Dynamics and Earthquake

Engineering, 134, 106177. https://doi.org/10.1016/j.soildyn.2020.106177

(C) 2020 This manuscript version is made available under the CC-BY-NC-ND 4.0 license

(http://creativecommons.org/licenses/by-nc-nd/4.0/).

\title{
Numerical Evaluation of the Soil Behavior During Pipe-Pile Installation Using Impact and Vibratory Driving in Sand
}

\author{
R. Daryaei, M. Bakroon, D. Aubram \& F. Rackwitz \\ Technische Universität Berlin, Chair of Soil Mechanics and Geotechnical Engineering, Berlin, \\ Germany
}

\begin{abstract}
Pipe-piles are installed using impact or vibratory driving which influences the soil in different ways including the void ratio and stress distribution. Such complex problems are hard to investigate on the field as well as using numerical methods. Here, a sophisticated numerical approach is employed to evaluate the soil behavior during pile installation. Also, a sensitivity analysis on the frequency and the impact duration is done for vibratory and impact driving, respectively. The investigation includes the required force of the pile installation, pile penetration behavior, plugging formation inside the pile, and the change of the soil state including the change in the horizontal stress and density around the pile during the installation. Results of the numerical model show several advantages of vibratory driving over impact driving in the dense sand including, reaching the designated depth using less momentum and work as well as more soil compaction.
\end{abstract}

Keyword: Pipe-pile installation, Impact and Vibratory driving, Soil-structure interaction, Multi-Material Arbitrary Lagrangian-Eulerian, Hypoplasticity, Granular soil

\section{INTRODUCTION}

The evaluation of the pile installation effects on the soil mechanical, load-bearing, and deformation behavior, respectively, is an important task in geotechnical engineering. This is particularly true for the steel pipe piles as a popular type of foundations for offshore wind turbines or oil rigs. The installation effects may reinforce or decrease the pile bearing capacity, and, in addition, the different driving methods may influence the soil in different ways. Moreover, choosing the right parameters within one driving method may also result in a different soil behavior and pile performance, leading to a quandary in choosing the proper driving method for a specific problem $[1,2]$.

In many situations, the piles are driven using impact or vibratory driving. During impact installation, the pile is pushed into the soil using a falling mass. This method more likely causes damage to the pile such as pile buckling [3,4]. In contrast, the vibratory driving method is a cheaper, faster, and less noisy alternative where the pile is driven using an axial periodic motion. In the case of non-cohesive soils, the resulting vibration due to the motion forms two different zones. In the zone near the pile shaft, the surrounding soil is loosened, which reduces both the soil resistance and its friction with the pile, making the penetration easier [3]. This small region is commonly referred to as a liquefaction zone. On the other hand, the regions far from the pile vicinity are compacted due to vibration. However, the estimation of the nominal resistance during driving has not yet been developed [1].

The evaluation of the soil behavior during driving using in situ tests or physical models is 
expensive and time-consuming, which emphasizes on the importance of a new cost-effective alternative. The numerical methods have therefore been chosen as they showed great potential as an evaluation tool in geotechnical problems in recent decades. Yet, the installation processes are still difficult to simulate using common numerical formulations due to significant and complex deformation [5]. In addition, the granular soils exhibit a non-linear behavior even during the initial loading stage which cannot be captured using simple elastoplastic-based constitutive models [6].

The motivation of this study is to use an advanced numerical model to investigate the possible effects of impact and vibratory driving of the pipe-piles on the soil behavior in terms of several major parameters including the pile penetration behavior, change of the soil state inside and outside the pile, plugging formulation, and the induced force on the pile during the driving. In addition, one of the influencing installation parameters for each driving technique, i.e. the vibratory and the impact duration for vibratory and impact driving, respectively, are varied. The outcome of this study shall provide a better outlook on the effect of each installation method on the soil characteristics.

\section{Literature review}

During the installation of pipe piles, the entrapped soil inside the pile sometimes moves as the pile is driven which is referred to as soil plugging. It is observed that this behavior increases the soil resistance and the pile behaves similarly as a close-ended pile, resulting in an additional resistance against driving [7]. Paik et al. [8] conducted two field tests with impact driven open- and closedended piles. They observed that the soil plug contributes to the pile system capacity to a percent of the base resistance of the close-ended pile. Though the piles were driven using the impact force only and no experiment regarding the vibratory driven piles was reported.

The initiation and the mechanism of plugging have been the subject of research in the last decade. Randolph et al. [9] argue that when the shear capacity of the plugged soil exceeds the bearing capacity of the plug end, plugging occurs. Based on this theory several empirical equations are derived which determine the possibility of plugging based on pile and soil characteristics. In recent works done by $\mathrm{Yu}$ et al. [10], new parameters are employed which captures the partially plugged soil effects. Nevertheless, the derived empirical equations do not consider the effect of various installation methods which are reported to have a significant effect on initiation or mitigation of plug formation [11].

Recently, Henke and Bienen [12] conducted experiments with impact and vibratory installation methods to study the plugging behavior in the pipe piles. It was reported that the dynamic energy of both impact and vibratory driving reduces the plug formation which reduces the soil resistance during the driving.

In a more extensive work, the effect of each installation method on the soil and the pile structures have been studied by Hartung [2]. It was concluded that by using the vibratory installation in loose granular soils, an increase in the pile tip resistance and shaft friction is achieved, provided that the installation frequency is close to the natural frequency of the soil. In case of impact driving, the soil exhibits different behavior based on its initial density. Depending on its loose or dense state, the soil around the pile shaft contracts or dilates, respectively. Nevertheless, an increase in stress 
is always observed in areas near the pile tip [2].

Concerning the numerical simulation of pile driving, special care should be given since such problems are considered in the category of large deformation problems, where significant distortions and complex movement of the soil are encountered. This causes several issues when classical numerical methods based on the Lagrangian formulation are used such as solution divergence, inadequate soil-structure interaction, and accuracy loss. Therefore, a robust alternative numerical technique should be devised.

One of the first attempts to numerically simulate the pile installation can be found in the work done by Cividini and Gioda [13] where a so-called "zipper method" was introduced. In addition, by using this method, Henke and Grabe [11] studied the impact and vibratory installation of piles. The void ratio and induced effective stress from both installation methods were compared. Recently, Heins et al. [14] simulated the vibratory pile installation of open-ended piles using this modeling technique. Different installation frequencies and driving energies were applied to the pile. It was concluded that more penetration is achieved using higher frequencies with lower energy. Despite its facilitation in modeling, the zipper-type technique imposes restrictions on the shape of the modeled pile and on the motion of the pile perpendicular to its axis. For the case of piles without a geometrically smooth tip, the method is unable to capture the compaction and rotational movement in the soil [15].

Recently, alternative numerical methods have been introduced which are able to capture the large soil deformations during pile installation. Most of these methods originate from the field of computational fluid dynamics, such as the Multi-Material Eulerian Arbitrary Lagrangian Eulerian (MMALE) method [5]. This method has been verified and validated for various geotechnical problems involving large deformation [16-18] and therefore shows itself as a potential and costeffective evaluation tool for such problems. A recent work done by Daryaei et al. [19] investigated the effect of frequency in achieved penetration depth in the vibratory installation of pipe piles.

\section{DEVELOPMENT OF THE NUMERICAL MODEL}

In this section, a brief description of the numerical model development is presented. Afterwards details of an experiment will be described which will be later used for the validation. Finally, the results are presented and discussed.

\subsection{The MMALE numerical approach}

The term Arbitrary Lagrangian-Eulerian (ALE) generally refers to the method developed by Hirt et al. [20], and others, to alleviate the mesh distortion issue in classical Lagrangian approaches and can be considered as an advanced mesh-based numerical formulation which benefits from the advantages of both classical Lagrangian and Eulerian element formulation in the Finite Element Method (FEM). In the Lagrangian formulation, the computational grid moves and deforms in accordance with the material particles, as if grid points are fixed to the particles. This constraint causes considerable shortcomings when the soil significantly deforms, including large distortion, solution divergence, or unreliable results [21]. On the contrary, the grid is fixed in the Eulerian formulation allowing the material to move independently through the grid. Therefore, after each 
calculation step, the solution must be transported to the initial grid. Despite solving the large deformations and vorticity issues, extra considerations for treating path-dependent material behavior and tracking material interfaces should be given in the Eulerian formulation [5]. In ALE, a three-step scheme is employed to advance the solution over each time increment. In the first step, the grid is allowed to deform as in the classical Lagrangian formulation. Then, a new less distorted grid is generated. Subsequently, the solution variables are transported to the new mesh as in the Eulerian formulation [22].

ALE methods can be subdivided into simplified ALE (SALE) and a Multi-Material ALE (MMALE) methods [5,17,23]. In SALE, material boundaries (free surfaces or material interfaces) are resolved in a Lagrangian way using edges and faces of the mesh. Hence, each mesh element can be filled with only one material. If several materials are present, the interfaces between them will force the boundary nodes to remain fixed or slide along it which deteriorates the mesh quality under large deformations, which is the same mesh distortion issue observed in classical Lagrangian methods. In the MMALE method, on the other hand, multiple materials can be present in a single element. Material interfaces are reconstructed and propagated through the mesh using the Volume of Fluid (VoF) or comparable methods [5]. In each element, the volume fraction of each material indicates how much of the element volume is occupied by that material. A value of 1 indicates an element completely filled with the material while a value of 0 indicates that the material is not present in the element. Values in between indicate that the material partially fills the element. The material volume fraction plays an important role in MMALE methods since it is used not only for interface tracking but also for the calculation of the degrees of freedom of the multi-material elements.

Figure 1 demonstrates the advantages of the MMALE method over the classical Lagrangian FEM. One of the main features of the MMALE is the capability of considering multiple materials inside one element which significantly improves the formulation in case of extremely large deformations. Usually, a material-free or void zone is defined within the grid without mass nor strength, so that other materials can flow into these regions of the physical space. For a more detailed theoretical background of the method, the reader is referred to [24].

\subsection{The Hypoplastic constitutive equation}

The mechanical behavior of soils, especially the granular soils, are very complex and require special treatments. One of the features of granular materials such as sand is its irreversible deformation, i.e. the deformed soil under pressure would not rebound if it is unloaded. In addition, the granular materials exhibit non-linear behavior from the early loading stages.[6]. Thus, simulating the mechanical behavior of such materials required special treatment.

Hence, an alternative concept called the hypoplasticity is introduced which captures the nonelastic deformation from the beginning of the loading and does not distinguish between elastic and plastic deformation. The hypoplastic constitutive model is popular for its simplicity where loading and unloading steps are considered in a single incrementally nonlinear equation. The stress rate of the granular material, $\dot{\mathrm{T}}$, is determined by the effective stress, $\mathrm{T}$, intergranular strain, $\delta$, and the void ratio, e $[6,25]$ : 
$\dot{\mathbf{T}}=\mathcal{M}(\mathbf{T}, \mathbf{D}, \mathrm{e}, \delta):, \mathbf{D}$

Besides the stress rate, the void ratio in the Eq. (1) is governed by the minimum and maximum void ratio, $\mathrm{e}_{\mathrm{i}}$, and $\mathrm{e}_{\mathrm{d}}$, respectively, as well as the critical void ratio, $\mathrm{e}_{\mathrm{c}}$.

Since the introduction of the hypoplasticity, numerous material models were developed to adapt the model to various loading conditions. In this study, the hypoplastic equation presented by Niemunis and Herle [25] is used which is the improved version of the hypoplastic equation developed by von Wolffersdorff [26]. The improvement addresses the previous issues of the model in reflecting the accurate strain accumulation during the cyclic loading [25]. Previous application of this version of the hypoplastic material model in large deformation geotechnical problems showed good agreement with experimental measurement results [27,28].

\subsection{Soil-structure interaction}

Here, a brief description of the employed contact scheme in MMALE for soil-structure interaction, the penalty contact scheme, is presented. In this method, the contact force is measured based on the arbitrary penetration of the parts. This is considered by adding an additional term (also called a penalty term) to the energy equation as follows [29]:

$$
\Pi=\mathrm{E}_{\mathrm{p}}+E_{k}+\frac{1}{2} k \Delta u^{2}
$$

Where $E_{\mathrm{p}}$ and $\mathrm{E}_{\mathrm{k}}$ are potential and kinetic energy, respectively, $k$ is the spring stiffness resembling the contact interface, and $u$ is the arbitrary penetration of two contact parts.

In the standard penalty formulation, the interface stiffness, $k$, is chosen to be approximately the same order of magnitude as the stiffness of the interface elements normal to the interface. To calculate the contact stiffness, $k_{c}$, the following equation is used for 2D shell elements:

$$
k_{c}=p_{f a c} \times \frac{A \times K}{d_{\min }}
$$

Where A, K, and d correspond to the area, bulk modulus and diagonal of the master shell element. $p_{f a c}$ is a stiffness factor which tunes the calculated contact interface. The equation above works fine in case of materials with similar bulk moduli. However, in case of high interface pressure, unacceptable penetration may occur. One can then scale the contact stiffness which in turn decreases the time step [30].

Alternatively, one may use a different equation as it proves to be more robust in case of soft materials [30]:

$$
k_{c}=0.5 \times p_{f a c} \times \frac{m}{\Delta t^{2}}
$$

Where $m$ is a function of the mass and $\Delta t$ is the time step. Again, the stiffness factor, $p_{f a c}$, can be varied. Please note that scaling the stiffness factor may cause some issues such as simulation instability, therefore the scaling value is limited.

There are several approaches to determine the $m$ which are listed in Table 2. The first three methods 
are based on the mass of both master and slave parts. The fourth one uses the bulk modulus of the structure. Alternatively, one can employ a user-defined curve correlating the penetration with the coupling pressure. In case of ALE, $m_{s}$ is the Lagrangian structure mass interpolated at coupling points from the Lagrangian nodal masses and $m_{m}$ is the ALE fluid mass interpolated at coupling points from the ALE nodal masses [31]. In this study, the Eq. (14) is used as it generally provides stable and reasonably accurate results.

\subsection{General remarks about the numerical model}

In this section, a description of modeling considerations using MMALE technique is presented where a pile is installed in the soil using a vibratory and impact load. An axisymmetric model is developed to reduce the computational costs. The model configuration which has been developed to back-calculate a small-scale experimental test at TU Berlin is shown in Figure 2.

The pile has $1.5 \mathrm{~m}$ height, $0.2 \mathrm{~m}$ diameter, and $0.004 \mathrm{~m}$ thickness which is modeled using the conventional 2D Lagrangian 4-node shell element formulation with one-point integration and a uniform element size of $0.004 \mathrm{~m}$. Since the ratio of diameter to thickness $(\mathrm{D} / \mathrm{t})$ is about 50 , it is reasonable to assume it as rigid.

For the soil and void, a mesh with $1.6 \mathrm{~m}$ height and $0.85 \mathrm{~m}$ radius with the one-point integration MMALE 2D shell element formulation is generated. A structured mesh, ranging from $0.004-0.04$ $\mathrm{m}$ element width is used. The mesh contains the soil up to a height of $1.4 \mathrm{~m}$. A void domain with $0.2 \mathrm{~m}$ height, which has neither mass nor strength, is defined above the soil material to enable the soil to move to this domain after penetration starts. The model is simulated using the fully drained analysis. The hypoplastic material model is adopted, whose corresponding material constants for Berlin sand are listed in Table 1 . The relative density of the soil is $\mathrm{I}_{\mathrm{D}}=75 \%$ (einitial $=0.465$ ). The initial stress in the soil is defined with assigning the gravity acceleration as $10 \mathrm{~m} / \mathrm{s}^{2}$ and using the horizontal earth pressure, $\mathrm{K}_{0}=0.5$. To define the coupling between pile and soil, penalty contact is defined. A tangential friction coefficient of 0.4 is assigned $(2 / 3 \tan \phi)$.

The container in the experiment is made of thick steel plates. The pile is fixed against horizontal movements while the horizontal sides of the soil are constrained against movements in directions perpendicular to their faces, with fixity applied in all directions at the bottom of the soil.

The numerical simulation consists of two phases. The pile is embedded at the depth of $0.1 \mathrm{~m}$ due to numerical stability considerations. Initially, the pile is let to penetrate by its own weight as was done in the experiment. Subsequently, the driving force is applied.

\subsection{Load definition in the numerical model}

The definition of the driving load is different for each installation method. The vibratory load is characterized by a centrifugal force and a frequency whereas the impact load is described by an applied energy per blow. In the case of the vibratory driving in this experiment, a vibratory motor is installed on the pile head with $1670 \mathrm{~N}$ centrifugal force and $23 \mathrm{~Hz}$ frequency. The imposed dead load on the pile due to self-weight, motor and mounting is about $F_{s}=419.3 \mathrm{~N}$. The frequency load is thus defined as follows: 


$$
F=F_{s}+F_{d} \sin (2 \pi f t)=419.3+1670 \times \sin (2 \pi \times 23 \times t)
$$

Where $F_{s}$ and $F_{d}$ are the static and centrifugal forces, respectively, and $f$ is the vibration frequency.

In the case of the impact driving, the weight and the height of the falling mass is often available in Figure 3, which should be converted to the applied load on the pile head. By assuming that the applied load on the pile is following an ideal sinusoidal function as in Figure 3, one can establish the following relations:

$$
\begin{aligned}
& F_{d}=f_{\text {max }} \sin \left(\frac{\pi t}{t_{1}}\right) \\
& \int_{0}^{t_{1}} F_{d} d t=-\left.f_{\text {max }} \frac{t_{1}}{\pi} \cos \frac{\pi t}{t_{1}}\right|_{0} ^{t_{1}}=f_{\text {max }} \frac{2 t_{1}}{\pi} \\
& \int_{0}^{t_{1}} F_{d} d t=m_{\text {hammer }} v_{\text {hammer }} \\
& v_{\text {hammer }}=\sqrt{2 g h} \\
& f_{\text {max }} \frac{2 t_{1}}{\pi}=m \sqrt{2 g h} \rightarrow f_{\text {max }}=\frac{\pi \mathrm{m} \sqrt{2 g h}}{2 \mathrm{t}_{1}}
\end{aligned}
$$

Where $\mathrm{m}$ and $\mathrm{h}$ are the mass and falling height of the drop weight, $t_{1}$ is the impact duration which represents the duration in which the falling mass and the pile are in contact, and $g$ is the gravity acceleration.

In a work done by Al-Kafaji [32], an efficiency factor, $\eta$, was introduced to the force equation, which takes into account the energy dissipation during impact as in Eq. (12). This is different than the efficiency factor proposed by Borja [33] as it was directly applied to the energy, not the force

$$
f_{\max }=\frac{\pi \eta \mathrm{m} \sqrt{2 \mathrm{gh}}}{2 \mathrm{t}_{1}}
$$

In the test, the total number of blows is 177 . For each blow, a mass of $22.1 \mathrm{~kg}$ was lifted to a height of $0.28 \mathrm{~m}$ and released, resulting in the energy of $60 \mathrm{~J}$ applied in a measured duration of $0.01 \mathrm{sec}$. The efficiency of load transfer based on the measurements done at TUB is $\eta=0.765$. By using the Eq. (12):

$$
f_{\max }=\frac{\pi \eta m \sqrt{2 g h}}{2 t_{1}}=\frac{\pi \times 0.765 \times 22.1 \times \sqrt{2 \times 9.81 \times 0.28}}{2 \times 0.01}=6.224 \mathrm{kN}
$$

The imposed dead load on the pile due to self-weight, motor and mounting is about $F_{s}=0.674 \mathrm{kN}$. The total duration of the experiment was 354 seconds which corresponds to an impact rate of 0.5 $\mathrm{Hz}$ (177 blows). The underlying reason for the long duration was the long intervals between each blow because the mass had to be lifted up and prepared for the next blow.

In the numerical model, however, this duration is computationally expensive. The intervals between each blow should be decreased to reach a suitable computation cost. However, the blow intervals should not be placed too close either. In principle, the optimum interval should be 
determined by evaluating the duration, in which the pile acceleration varies significantly. In other words, the next blow should be applied at the time, at which the pile is in equilibrium. Figure 4 shows the acceleration history of the pile due to one impact. In this case, the interval of 0.15 is adequately large enough to avoid overlapping in the acceleration of the pile. The loading history curves of both pile driving methods are shown in Figure 5.

To facilitate the comparison of the different driving methods, the momentum is used as a comparison parameter, which reflects the duration of the applied load $(M=F . \Delta t)$. Here, $F$ and $\Delta t$, are the applied force and its corresponding loading time duration, respectively. In this way, one can gain a better comparison of two different driving methods. The interpretation of the momentum is the area under the load history curves such as those shown in Figure 5. In the case of the vibratory load, only the positive area is considered since the negative area corresponds to the force applied to lift the pile and is therefore not applied to the soil.

\subsection{Numerical model validation}

The results of the numerical models of vibratory and impact installation are validated against experiments conducted at the laboratory of the Chair of Soil Mechanics and Geotechnical Engineering at Technische Universität Berlin (TU Berlin). Details regarding the test set-up can be found in the published work done by Remspecher et al. [34]. The experiment includes a halfcylindrical pile with $1.5 \mathrm{~m}$ length, $0.004 \mathrm{~m}$ thickness, and $0.2 \mathrm{~m}$ outer diameters placed in a container filled with the Berlin sand and consists of three rigid steel walls and one glass panel. The pile movement is constrained in the horizontal direction using pile guides. To measure pile penetration; two displacement sensors are installed on the pile.

The deformed shape of the soil inside and outside the pile is compared with those captured from the experiment for both impact and vibratory driving in Figure 6. The numerical model provides an acceptable estimation of the surface shape. Nevertheless, the height of the entrapped soil inside the pile is overestimated in the case of impact driving. On the other hand, the soil surface calculated in the numerical model is in good agreement with what is observed in the experiment.

Figure 7 shows the comparison of the pile tip depth and displacement curves from the numerical models against experimental measurements. The pile tip displacement curve is simply obtained by subtracting the initial embedment depth from the pile tip depth curve. As mentioned in section 3.4 the pile is let to penetrate by its own weight in both the experiment and the numerical model. The corresponding initial penetration of the pile due to its own weight plus the 10-cm wished-in depth in the numerical model is $13 \mathrm{~cm}$, whereas the pile penetration due to its own weight in the experiment is measured $12 \mathrm{~cm}$. Nevertheless, both curves are generally in good agreement with experimental measurements and capture the penetration trend.

In the case of impact driving (Figure 7a), the penetration curve obtained from the numerical model with the efficiency factor of 0.765 was less accurate compared to the vibratory driving. The loading was the only different condition between the cases of impact and vibratory driving. For the sake of comparison, the contact parameters in the numerical models have to be maintained since the same model pile was used in the experiments with impact as well as vibratory driving. In Authors' point of view, the efficiency factor in the impact load equation has a high level of uncertainty and 
is difficult to determine in experiments. In Figure 8 the effect of this parameter on the penetration curves is illustrated. Therefore, it may be argued that an efficiency factor between 0.65 and 0.70 is a better choice despite the experimentally measured value of 0.765 . In the case of an efficiency factor of 0.7 , a very good agreement is achieved. The difference between the final depth of the pile in the numerical and the experiment is less than 5\%. The designated depth in the experiment is achieved with around 150 blows, indicating a difference of around $15 \%$ compared to the experiment.

By comparing the pile tip displacement curves for vibratory driving in Figure $7 \mathrm{~b}$, an initially good agreement is observed which continues until 8 seconds of the simulation. Then, a difference between the numerical results and the experiment is observed which is somewhat around $5 \%$. Nevertheless, the numerical model is argued to reproduce the experimental results reasonably and therefore can be used as a reference model for the following parametric studies.

\section{Parametric study}

To achieve a better understanding of how each driving method affects the driving experience, the primary parameter of each installation method is varied throughout the numerical tests. In all cases, the numerical model with general properties mentioned in section 3.4 is used.

\subsection{Effect of impact load magnitude and duration in impact installation}

In the case of impact driving, the engineers may be only interested in the hammer mass and its falling height as these parameters are easy to control in practice. Yet, concerning the Eq. (10), these parameters are merely reflected in the numerical model as a force. Obtaining the impact duration, $t_{1}$, seems to play an important role in the calculation of the maximum impact force. Hence, an investigation is performed here to see its possible effects. The impact duration is varied in the value range of $0.0005-0.02$ seconds. The corresponding forces are calculated according to Eq. (10). The load application history of each case is shown in Figure 9. As the impact duration, $t_{1}$, increases, the maximum applied force, $F_{\max }$, is decreased, resulting in the same momentum for each blow for each case.

Figure 10 shows the pile displacement curves for each case. The penetration trends of all cases are identical, i.e. a relatively fast penetration rate at initial stages which decreases as penetration continues. Generally speaking, by an increase (decrease) in $t_{1}$, a higher (less) pile displacement is observed. Initially, the curves are somewhat identical up to 30 blows. Afterward, two curves attributed to those with long impact durations, i.e. $t_{1}=0.02$, and $0.015 \mathrm{sec}$, show less penetration compared to other curves which can hence be classified based on the pile depth as "case 1". The other cases which provided relatively identical penetration curves are then categorized as "case 2". A difference between the curves within case 2 appear at the final stages of the penetration, say after 120 blows. At the end of the driving, about $25 \%$ more penetration is observed in curves of case 2 compared to those in case 1 . Thus, by using less impact duration, more penetration can generally be expected. Minimal differences are observed between the cases of $t_{1}=0.0005$ and 0.001 seconds in case 2 as well as $t_{l}=0.02$ and $0.015 \mathrm{sec}$ in case 1 . Therefore, it may be concluded that further decrease/increase in the impact duration/maximum applied force may not provide a significantly more penetration than what is shown in Figure 10. 
To investigate the possible effects of different impact durations, three cases of impact driving with $t_{1}=0.001,0.01$, and $0.02 \mathrm{sec}$, are compared at two different pile tip depths, $0.6 \mathrm{~m}$ and $0.8 \mathrm{~m}$ (3D and $4 \mathrm{D}$, respectively), as depicted in Figure 10. The comparison criteria include the change in horizontal stress and void ratio.

Figure 11 depicts the calculated horizontal stress in two horizontal stations at the depths of $1.5 \mathrm{D}$ and 3.5D for two pile depths. In the first case, where the pile is at the depth of 3D, the station at $1.5 \mathrm{D}$ is above the pile tip whereas the station at $3.5 \mathrm{D}$ is below. The upper station shows generally limited increase in the horizontal stress (Figure 11a). In the case of $t_{1}=0.02 \mathrm{sec}$, the curves are oscillating more compared to the other two cases. A sudden increase is observed at a distance of 2D from the pile shaft. Meanwhile, the lower station shows a significantly higher increase in horizontal stress up to seven times the initial horizontal stress inside and five times outside the pile (Figure 11b). The values inside the pile are larger than outside. The significance of the increase in horizontal stress is observed until a distance of $2 \mathrm{D}$ from the pile shaft. Again, in the case of $t_{1}=0.02$ $\mathrm{sec}$, the maximum horizontal stress inside the pile is observed.

After the pile reaches the depth of $4 \mathrm{D}$, the horizontal stress condition is almost maintained at the upper station (Figure 11c), where only a limited increase is observed. At the station at 3.5D (Figure 11d), on the other hand, where the pile has passed the station and now is at a lower depth, the horizontal stresses are 50\% less inside the pile, compared to the previous case (Figure 11b), but still indicate a significant change compared to the initial horizontal stress. This time, the horizontal stress near the pile shaft is less than the initial state. Then, the horizontal stress increases until it reaches a distance of about $1 \mathrm{D}$. Concerning the induced horizontal stress values inside the pile, the case with $t_{1}=0.001 \mathrm{sec}$ gave the least value while the other two cases show $50 \%$ more. Comparing Figure 11d and Figure 11b, the overall horizontal stress inside the pile is decreased to half. Additionally, one may notice that after a horizontal distance of 1D from the pile shaft, identical stress values are achieved which indicate that between the depths of 3D and 4D, most of the driving effects are concentrated up to a distance of 1D from the pile shaft. In addition, the horizontal stress inside the pile is more than what is observed outside the pile, indicating the occurrence of soil plugging.

In Figure 12, the change in void ratio at the same stations is plotted. In Figure 12 a, c, and d (where the pile tip is located deeper than the stations), the void ratio inside the pile varies dramatically from a significant dilatancy near the pile shaft due to the shearing of the dense sand $\left(\mathrm{I}_{\mathrm{D}}=75 \%\right)$, to a compaction in the center of the pile due to soil plugging. Outside the pile, the same dilatancy is observed near the pile shaft due to the same reason. After a small distance from the pile shaft, significant compaction (roughly 15\% compared to the initial void ratio) is observed up to a distance of about 1D, which is almost similar to the influenced area observed in the horizontal stress curves in Figure 11b. In Figure 12b, where the pile tip is located above the station, no dilatancy around the pile shaft is observed and only compaction is shown and all the cases exhibit similar trend.

The case with $t_{1}=0.02 \mathrm{sec}$, exhibited the maximum compaction and dilatancy near the pile shaft in Figure 12a, c, and d. This becomes evident in some cases, like in Figure 12a, where the minimum void ratio outside the pile shaft, in this case, is about $10 \%$ more than the other two cases, $t_{1}=0.001$ and $0.01 \mathrm{sec}$. Also, a relatively high dilation is observed inside the pile in Figure 12d. The other two cases exhibit generally the same trend. 
Consequently, it can be concluded that in this example, the effect of further reduction of the impact duration and increasing the maximum force according to Eq. (10), becomes marginal at the $t_{1}=$ $0.01 \mathrm{sec}$. Increasing the impact duration, on the other hand, results in quiet distinct differences on the outcome, for instance the change in the penetration depth and more compaction/dilation. It is suspected that by increasing the duration, the dynamic or impact effects are diminished, leading to different behavior in the soil during the driving.

\subsection{Effect of frequency in the vibratory installation}

In this case, six frequencies are chosen, $f=16,19,23,27,30$, and $40 \mathrm{~Hz}$. The centrifugal force is maintained in all cases. The resulting penetration curves are shown in Figure 13. The correlation of the pile displacement curves with the frequency is not linear meaning that by increasing the frequency a higher pile displacement depth is not necessarily achieved. The maximum achieved pile tip depth corresponds to the $f=23 \mathrm{~Hz}$ whereas the least depth is observed at $f=40 \mathrm{~Hz}$. In the case of $f=16$ and $19 \mathrm{~Hz}$, the model terminated before reaching the desired time where the pile stopped penetrating further which may be the underlying reason of the model termination.

To investigate the effect of frequency further, the eigenfrequencies of the system have been calculated using a numerical eigenvalue analysis. The implicit solver in conjunction with a classical Lagrangian element formulation is used. For the sake of brevity, the description of the analysis method is not explained here, and the reader is referred to available references in the literature such as [35]. To this extent, a simple elastic material model with similar properties of the Berlin sand has been used instead. The elastic modulus is calculated by assuming a Poisson's ratio of 0.3 and the bulk modulus calculated from the hypoplastic material model [36]:

$$
K=\frac{1}{3} \frac{h_{s}}{n}\left(1+\frac{1}{e_{p}}\right)\left(\frac{3 p_{s}}{h_{s}}\right)^{1-n}=\frac{1}{3} \frac{2.3 \times 10^{8}}{0.3}\left(1+\frac{1}{0.465}\right)\left(\frac{3 \times 10^{5}}{2.3 \times 10^{8}}\right)^{1-0.3}=7.7 \times 10^{6} \mathrm{~Pa}
$$

The experiment is conducted in a container which represents a half model of the real problem. Therefore, a numerical model with either exact or half of the test size (which results in a quarter model) can be used. Alternatively, an axisymmetric numerical model can be developed as of this study. Hence, three models with the above assumptions are generated to evaluate the resulting eigenfrequencies. Table 3 list the first five eigenfrequencies of each model. In the case of the axisymmetric model, the first two eigenfrequencies are about $14 \mathrm{~Hz}$ and $22 \mathrm{~Hz}$. For the other two models, quarter and half model, the similar frequencies are obtained. However, several other values in this range were also observed. This can be attributed to the applied boundary conditions since the resulting mode shapes are asymmetric and cannot be captured using an axisymmetric model. Nevertheless, all models determined values around $14 \mathrm{~Hz}$ and $22 \mathrm{~Hz}$ as eigenfrequencies of the system. This finding may explain the maximum penetration obtained by driving the pile with a frequency near the natural frequency of the system which is around $23 \mathrm{~Hz}$ in this case. Also, a relative lower horizontal stress value is reached as the pile is installed with a frequency of $23 \mathrm{~Hz}$.

To study the effects of driving frequency on the soil, the change in void ratio due to vibration is presented in Figure 14a-b. The results are shown at two stations with depths of 1.5D and 2.5D at the pile depth of $2 \mathrm{D}$, resulting in a station above and one below the pile tip. At the upper station 1.5D, the soil inside the pile and outside the pile is mostly compacted (Figure 14a). The soil is 
influenced up to a lateral distance of 1.5D from the pile shaft. For all cases, a thin area of the soil near the pile shaft is dilated significantly. Nevertheless, the change in driving frequency does not show a remarkable change. One may only mention a slight increase in the influence area of the soil outside the pile shaft for the case of $f=40 \mathrm{~Hz}$. In contrast, a clear difference is observed at the lower station 2.5D (Figure 14b), where the case of $f=23 \mathrm{~Hz}$, induces the most compaction inside and outside the pile. The horizontal influenced distance is decreased compared to the upper station to $1 \mathrm{D}$. Since the station is underneath the pile, no dilation zone is observed around the pile shaft. In the case of $f=40 \mathrm{H}$, no considerable change in the void ratio is noticed. Compared to upper station in Figure 14a, the increase in the void ratio measured at the lower station is less than the upper station which may be attributed to the high entrapment/confinement caused by the pile shaft.

Similarly, the horizontal stress is also measured at the aforementioned stations and shown in Figure $14 \mathrm{c}-\mathrm{d}$. At the upper station, the maximum horizontal stress is observed inside the pile for the case of $f=23 \mathrm{~Hz}$, followed by the cases of $f=16 \mathrm{~Hz}$ and $f=40 \mathrm{~Hz}$, respectively (Figure 14c). Outside the pile shaft, the soil at a small horizontal distance, say up to $0.5 \mathrm{D}$, shows lower horizontal stress compared to the initial state. Afterward, the lateral stress increases. Also, a rather high oscillation in the results of the $f=40 \mathrm{~Hz}$ is seen. At the lower station under the pile tip, the maximum lateral stress is attributed to the cases of $f=23$ and $16 \mathrm{~Hz}$ (Figure 14d). In these cases, the maximum horizontal stress is increased two and five times, respectively. Similar to the upper station, the case $f=40 \mathrm{~Hz}$ shows high oscillation in the results.

The plugging can also be checked by comparing the horizontal stress inside and outside the pile. It is worth to mention that the visual determination of plugging may not be a proper method of evaluation as not the whole soil regime inside the pile may contribute to plugging. In other words, the upper part of the soil may merely act as a surcharge. In addition, the hypoplastic constitutive equation has limitation in capturing the volumetric change on low confinement area and therefore it may overestimate the heaving. Therefore, the horizontal stress is used as an indicator. In case of $f=23 \mathrm{~Hz}$ (Figure 14c), one may argue that the soil plug has formed since the horizontal stress inside the pile is more than the one outside the pile, unlike the case $f=16$ and $40 \mathrm{~Hz}$, where no significant change can be detected. The underlying reason may be the closeness of the driving frequency $f=23$ $\mathrm{Hz}$ to the eigenfrequency of the system.

Concerning the results discussed above, choosing a frequency close to the eigenfrequency of the system cause some distinct effects in the soil and the pile driving. For instance, one may reach a further penetration depth, a higher compaction intensity, and also high horizontal stresses resulting in plug formation. Hence, one may argue that the driving frequency $f=23$ is the suitable frequency for this installation problem.

\subsection{Discussion of impact and vibratory installation}

The comparison of two driving methods is conducted by penetrating the pile to the same depth which is $2.5 \mathrm{D} \mathrm{m}$ in this study. The results of the models developed for validation in sections 3.43.6 are used here.

One challenging point is the comparison criterion for both driving techniques. In the case of impact driving, the impact energy is reported whereas in the vibratory driving, the force is given. To the 
best knowledge of the authors, there had been no previous common parameter or criterion for impact and vibratory driving. On one side, comparing the applied energies for each method is not possible since calculating the applied energy on the pile during vibratory driving is not possible. Therefore, the momentum is chosen since it is easily calculated for both methods by integrating the applied total force per time. The properties of each load along with the calculated momentum values are listed in Table 4. By using the vibratory driving, the designated depth is reached using about $20 \%$ less momentum of the one in the impact driving.

In Figure 15, the void ratio distribution at the depth of $0.47 \mathrm{~m}$ for both the impact and vibratory pile driving is shown. In both cases, the soil is influenced, however, the influence zone is wider and more intense in the case of vibratory driving. The compacted zone may provide additional horizontal support for the pile after installation. In addition, different soil behavior is observed inside the pile for impact and vibratory driving, i.e. loosening is observed inside the pile for the former case while compaction is observed for the latter case. At the pile shaft, a loosening zone is observed which is due to disturbance. This zone is $80 \%$ larger in case of the impact of driving.

Initially, it seems that heaving has occurred in both cases in Figure 15 and therefore no plugging has taken place. However, this may not be generally true as the lower part of the soil may have undergone plugging while the upper part acts as a surcharge. Figure 16 is therefore presented to compare the horizontal stress inside and outside the pile at the same pile tip depth. The horizontal stress inside the pile exceeds the values outside in both cases, which can be therefore concluded that the soil inside the pile plugs [12]. In the case of impact driving, more horizontal stress inside the pile is obtained compared to the one in the vibratory driving which is almost two times in the peak horizontal stress. Also, the stress outside and near the pile tip is quiet smooth and uniform in the case of vibratory driving, unlike the impact driving where the trend is oscillatory.

In addition, the velocity field in the soil regime around the pile tip is plotted in Figure 17. According to the definition of plugging, the soil inside the pile should move with the pile movement. Here, for both cases of driving and for both upward and downward movement of the pile, the soil tends to follow the pile direction and therefore the plugging occurrence can be justified.

Furthermore, three stationary measuring points are used to evaluate the change in horizontal stress during the pile driving. The points are chosen close to the pile shaft with $\mathrm{r}=0.12,0.16$, and $0.21 \mathrm{~m}$ from the axis of symmetry. The results are shown in Figure 18. By using the impact driving, a significantly more horizontal stress in all stations is induced than the case of the vibratory driving. The effects of driving on the horizontal stress for both cases start from a depth of 1D and ends at the depth of $2.5 \mathrm{D}$, however, the rate of increase in the horizontal stress is more in the impact driving. In both cases, the maximum horizontal stress is recorded at the time the pile passed the stations.

The increase in the horizontal stress in the case of impact driving (Figure 18 left) varies generally from two to fifteen times the initial stress. The maximum horizontal stress is observed at the station of $\mathrm{r}=0.21 \mathrm{~m}$ in the case of impact driving. The underlying reason for this high horizontal stress may be that the shear failure zone passes through this station. 
In the case of vibratory driving, the increase in horizontal stress (Figure 18 right) is between three to seven times the initial state. A limited increase is observed for the stations of $r=0.16 \mathrm{~m}$ and $0.21 \mathrm{~m}$, almost three times the initial stress. Unlike the case of impact driving, the maximum horizontal stress is recorded at the station $\mathrm{r}=0.12 \mathrm{~m}$ which is the closest one to the pile shaft.

One of the interesting outputs of the numerical model in this study is the failure pattern observed in the case of two installation problems. To the knowledge of the authors, not much is known about the failure patterns during pile installation. Mostly, the works done by Meyerhof [37] and Vesić [38] are widely accepted and practiced in geotechnical field which are improved versions of the original work done by Prandtl [39]. However, the theories suffer from limitations such as the pile geometry, i.e. only the closed-ended piles are considered. Nevertheless, concerning the fact that plugging has occurred in the pile (based on the radial stress distribution in Figure 16 and soil movement in Figure 17), a similar behavior can be expected as the plugged pile is closely related to a closed-ended pile. Here, the numerical results of the in-plane shear failure for both cases of driving at the pile tip depth of 2.5D are compared in Figure 19 with the theoretical failure patterns from Vesić [38], which indicates a so-called "punching shear failure". In this case, the failure pattern does not fully form up to the surface (unlike the general shear failure). Depending on the soil relative density, the punching failure can occur at shallow depths but is the dominating failure pattern at greater depths regardless of the relative density [38]. Generally speaking, the failure pattern in both impact and vibratory driving cases take the failure form of the punching shear, as if the pile was closed-ended. The triangular-shaped failure zones underneath the pile is similar to the Rankine active zone which is followed by a bubble-shaped zone which may be assumed as the transitional zone. In the case of impact driving, an additional zone is observed exactly below the active zone unlike the case of vibratory driving. Hence, it may be argued that the choice of the installation method may affect the induced failure shape. Yet, more investigation shall be conducted about this matter.

In Figure 20, the induced force in the pile during penetration for each case is drawn. In the Eurocode EC7 [40], the failure criterion for the pile is described as a load required to cause a settlement equal to $10 \%$ of the pile diameter. Therefore, the required force to penetrate the pile can give an insight regarding the bearing capacity of the pile. In the case of vibratory driving, less force is required to reach the designated depth. In this case, the maximum force required to drive the pile is $70 \%$ of the case of impact driving. This can be considered as an advantage of vibratory driving since by using high forces the pile may suffer plastic deformation, e.g. local/global buckling, which in turn reduces the pile performance.

The required force in the case of vibratory driving increases up to the depth of $1 \mathrm{D}$ and then remains constant until the depth of $1.5 \mathrm{D}$. It is good to notice that the pile force comprises of the tip and shaft resistance, thus one may argue that by using the vibratory driving the shaft resistance is up to some extent reduced. Having in mind that the area under the curve corresponds to the work, it can be concluded that about one-third of the work done in the impact driving is required in the case of vibratory driving.

Based on the discussed outcomes, it is evident that by using different installation methods, one may reach different soil response including the induced horizontal stress and soil densification. Here, by using the vibratory driving, several advantages are achieved compared to the impact 
driving such as obtaining more compaction in the soil (see Figure 15), less induced horizontal stress (Figure 16 and Figure 18), leading to the less required work for pile installation (Figure 20).

\section{CONCLUSIONS}

In this study, the advanced numerical approach MMALE with a sophisticated hypoplastic constitutive equation is used to investigate the effects of the impact and vibratory installation of a pipe-pile in a granular soil. The investigation criteria include the induced horizontal stress inside and outside the pile, change in void ratio, and pile displacement depth. To gain a better understanding of the installation effects, a parametric study for each driving method is conducted. In the case of impact driving, the impact duration and its respective maximum force were changed whereas, in the case of vibratory driving, the driving frequency is varied with no change in the centrifugal force. In each case, the momentum, which reflects the load application duration, is maintained.

In the case of impact driving, the following points are observed:

- By increasing the force and reducing the impact duration, more penetration is generally achieved, however, in case of impact durations smaller than $10 \mathrm{msec}$, the increase in the final pentation depth is up to $10 \%$ (Figure 10).

- By increasing the impact duration, several effects appear such as high oscillation in the horizontal stress and drastic soil compaction (Figure 11).

In the case of vibratory driving, the following points are observed:

- A frequency near the natural system frequency provided the maximum pile displacement. Values above or below this frequency lead to less pile displacement (Figure 13).

- The horizontal distance of the influenced zone due to vibration increased linearly by increasing the vibration frequency to higher values (Figure 14).

Concerning the two driving methods, the soil exhibited a different response for each driving case. The differences can be summarized to the following points:

- During the vibratory driving, a wider area with more intensity is compacted (Figure 15,).

- The maximum lateral stress in case of impact was more than two times of what was induced in the vibratory driving (Figure 18).

- The failure pattern of the soil during the driving was different (Figure 19).

- The vibratory driving method reached the desired pile displacement depth using $20 \%$ less momentum, since less horizontal stress around the pile shaft is induced which reduces the frictional force and thus the driving resistance (Table 4).

- About $70 \%$ of the impact force was required to drive the pile using vibratory method (Figure 20).

For future works, a coupled formulation can be implemented to capture pore water and drainage 
conditions. This is crucial for offshore projects where the presence of water plays an important role. Also, using the suggested approach it may be possible to study the pile deformation and wave propagation during driving with simply assuming an elastic pile.

\section{ACKNOWLEDGEMENT}

The authors are thankful for the partial financial support obtained from Deutscher Akademischer Austauschdienst (DAAD) with grant number 91561676 and the Elsa-Neumann scholarship of city Berlin (NAFOEG) with grant number T68001. Also, the authors are thankful to innogy SE for the partial financial support within the CAFÉ project.

\section{REFERENCES}

[1] J H, F R, G L, Robinson R, Becker E. Design and Construction of Driven Pile Foundations - Comprehensive Design Examples. 2016.

[2] Hartung M. Einflüsse der Herstellung auf die Pfahltragfähigkeit in Sand. Braunschweig, Techn. Univ., 1994.

[3] Holeyman A, Whenham V. Critical Review of the Hypervib1 Model to Assess Pile VibroDrivability. Geotechnical and Geological Engineering 2017;35:1933-51. doi:10.1007/s10706-017-0218-8.

[4] Rausche F, Webster S. Behavior of Cylinder Piles During Pile Installation. Contemporary Issues In Deep Foundations, Reston, VA: American Society of Civil Engineers; 2007, p. 1-13. doi:10.1061/40902(221)8.

[5] Benson DJ. Computational methods in Lagrangian and Eulerian hydrocodes. Computer Methods in Applied Mechanics and Engineering 1992;99:235-394. doi:10.1016/00457825(92)90042-I.

[6] Kolymbas D. Constitutive Modelling of Granular Materials. Berlin, Heidelberg: Springer Berlin Heidelberg; n.d. doi:10.1007/978-3-642-57018-6.

[7] De Nicola A, Randolph MF. The plugging behaviour of driven and jacked piles in sand. Géotechnique 1997;47:841-56. doi:10.1680/geot.1997.47.4.841.

[8] Paik K, Salgado R, Lee J, Kim B. Behavior of Open- and Closed-Ended Piles Driven Into Sands. Journal of Geotechnical and Geoenvironmental Engineering 2003;129:296-306. doi:10.1061/(ASCE)1090-0241(2003)129:4(296).

[9] Randolph MF, Leong EC, Houlsby GT. One-dimensional analysis of soil plugs in pipe piles. Géotechnique 1991;41:587-98. doi:10.1680/geot.1991.41.4.587.

[10] Yu F, Yang J. Base Capacity of Open-Ended Steel Pipe Piles in Sand. Journal of Geotechnical and Geoenvironmental Engineering 2012;138:1116-28. doi:10.1061/(ASCE)GT.1943-5606.0000667.

[11] Henke S, Grabe J. Numerical investigation of soil plugging inside open-ended piles with respect to the installation method. Acta Geotechnica 2008;3:215-23. doi:10.1007/s11440008-0079-7.

[12] Henke S, Bienen B. Centrifuge tests investigating the influence of pile cross-section on 
pile driving resistance of open-ended piles. International Journal of Physical Modelling in Geotechnics 2013;13:50-62. doi:DOI 10.1680/ijpmg.12.00012.

[13] Cividini A, Gioda G. A simplified analysis of pile penetration. In: Swoboda G, editor. Proceedings of 6th International Conference of Numerical Methods in Geomechanics, Innsbruck, Austria: A. A. Balkema; 1988, p. 1043-9.

[14] Heins E, Hamann T, Grabe J, Hannot S. Numerical investigation of the influence of the driving frequency during pile installation of tubular piles. Geotechnik 2016;39:98-109. doi:10.1002/gete.201600014.

[15] Qiu G, Henke S, Grabe J. Application of a Coupled Eulerian-Lagrangian approach on geomechanical problems involving large deformations. Computers and Geotechnics 2011;38:30-9. doi:10.1016/j.compgeo.2010.09.002.

[16] Bakroon M, Daryaei R, Aubram D, Rackwitz F. Numerical evaluation of buckling in steel pipe piles during vibratory installation. Soil Dynamics and Earthquake Engineering 2019;122:327-36. doi:10.1016/j.soildyn.2018.08.003.

[17] Bakroon M, Daryaei R, Aubram D, Rackwitz F. Multi-Material Arbitrary LagrangianEulerian and Coupled Eulerian-Lagrangian methods for large deformation geotechnical problems. In: Sagaseta C, editor. Numerical Methods in Geotechnical Engineering (NUMGE 2018), Porto, Portugal: 2018, p. 8.

[18] Daryaei R, Eslami A. Settlement evaluation of explosive compaction in saturated sands. Soil Dynamics and Earthquake Engineering 2017;97:241-50.

doi:10.1016/j.soildyn.2017.03.015.

[19] Daryaei R, Bakroon M, Aubram D, Rackwitz F. Numerical Investigation of the Frequency Influence on Soil Characteristics During Vibratory Driving of Tubular Piles. In: Shehata H, Desai CS, editors. International Congress and Exhibition "Sustainable Civil Infrastructures: Innovative Infrastructure Geotechnology, Cham: Springer International Publishing; 2019, p. 48-61. doi:10.1007/978-3-030-01926-6_3.

[20] Hirt CW, Amsden AA, Cook JL. An arbitrary Lagrangian-Eulerian computing method for all flow speeds. Journal of Computational Physics 1974;14:227-53. doi:10.1016/00219991(74)90051-5.

[21] Belytschko T, Liu WK, Moran B. Nonlinear finite elements for continua and structures. vol. 104. Chichester: John Wiley; 2000. doi:10.1016/S0065-230X(09)04001-9.

[22] Bakroon M, Daryaei R, Aubram D, Rackwitz F. Arbitrary Lagrangian-Eulerian Finite Element Formulations Applied to Geotechnical Problems. In: Grabe J, editor. Numerical Methods in Geotechnics, vol. 41, Hamburg, Germany: BuK! Breitschuh \& Kock GmbH; 2017, p. 33-44. doi:978-3-936310-43-6.

[23] Bakroon M, Daryaei R, Aubram D, Rackwitz F. Investigation of Multi-Material ALE and Coupled Eulerian-Lagrangian large-deformation analysis. International Journal of Geomechanics 2020;Accepted. doi:10.1061/(ASCE)GM.1943-5622.0001723.

[24] Aubram D, Rackwitz F, Savidis SA. Contribution to the Non-Lagrangian Formulation of Geotechnical and Geomechanical Processes. In: Triantafyllidis T, editor. Holistic Simulation of Geotechnical Installation Processes - Theoretical Results and Applications, ch. 3. Lecture Notes in Applied and Computational Mechanics, vol. 82, Springer 
International Publishing; 2017, p. 53-100. doi:10.1007/978-3-319-52590-7_3.

[25] Niemunis A, Herle I. Cohesionless soils with elastic strain range. Mechanics of CohesiveFrictional Materials 1997;2:279-99.

[26] von Wolffersdorff P. A hypoplastic relation for granular materials with a predefined limit state surface. Mechanics of Cohesive-Frictional Materials 1996;1:251-71.

[27] Bakroon M, Daryaei R, Aubram D, Rackwitz F. Implementation and Validation of an Advanced Hypoplastic Model for Granular Material Behavior. 15th International LSDYNA® Users Conference", Detroit, Michigan, USA: 2018, p. 12.

[28] Bakroon M, Aubram D, Rackwitz F. Geotechnical large deformation numerical analysis using implicit and explicit integration. 3rd International Conference on New Advances in Civil Engineering 2017:26-36.

[29] Wriggers P. Computational contact mechanics, second ed., Springer. 2006. doi:10.1007/978-3-540-32609-0.

[30] Hallquist J. LS-DYNA® theory manual. California: Livermore Software Technology Corporation; 2006.

[31] Personal communication with Dr. JM Kennedy 2019.

[32] Al-Kafaji IKJ. Formulation of a Dynamic Material Point Method ( MPM ) for Geomechanical Problems. Ridderprint BV; 2013.

[33] Borja RI. Dynamics of pile driving by the finite element method. Computers and Geotechnics 1988;5:39-49. doi:10.1016/0266-352X(88)90015-8.

[34] Remspecher F, Le VH, Rackwitz F, Herwig V, Matlock B. Vibratory Driven Installation of Monopiles - An Experimental Investigation of the Soil-Pile Interaction. In: Randolph M, Doan D, Tang A, Bui M, Dinh V, editors. Proceedings of the 1st Vietnam Symposium on Advances in Offshore Engineering, Hanoi, Vietnam: Springer, Singapore; 2019, p. 171-6. doi:10.1007/978-981-13-2306-5_22.

[35] Bathe KJ, Saunders H. Finite Element Procedures in Engineering Analysis. vol. 106. Englewood Cliffs and London: Prentice-Hall; 1984. doi:10.1115/1.3264375.

[36] Herle I, Gudehus G. Determination of parameters of a hypoplastic constitutive model from properties of grain assemblies. Mechanics of Cohesive-Frictional Materials 1999;4:46186. doi:10.1002/(SICI)1099-1484(199909).

[37] Meyerhof GG. The Ultimate Bearing Capacity of Foudations. Géotechnique 1951;2:30132. doi:10.1680/geot.1951.2.4.301.

[38] Vesić AS. Bearing capacity of deep foundations in sand. Highway Research Record 1963:112-53.

[39] Prandtl L. Über die Härte plastischer Körper. Nachrichten von Der Gesellschaft Der Wissenschaften Zu Göttingen, Mathematisch-Physikalische Klasse 1920:74-85. doi:10.1007/978-3-662-11836-8_7.

[40] Bond AJ, Schuppener B, Scarpelli G, Orr TLL. Eurocode 7 : Geotechnical Design Worked examples. European Commission; 2013. doi:10.2788/3398. 
Tables

Table 1 Hypoplastic material constants for the dense Berlin sand $\left(\mathrm{I}_{\mathrm{D}}=0.75\right)$

\begin{tabular}{|c|c|c|c|c|c|c|c|c|c|c|c|c|}
\hline$\varphi_{\mathrm{c}}\left[^{\circ}\right]$ & $h_{\mathrm{s}}[\mathrm{MPa}]$ & $n$ & $e_{\mathrm{d} 0}$ & $e_{\mathrm{c} 0}$ & $e_{\mathrm{i} 0}$ & $\alpha$ & $\beta$ & $m_{R}$ & $m_{T}$ & $R$ & $\chi$ & $\beta_{r}$ \\
\hline 31.5 & $230^{*}$ & 0.3 & 0.391 & 0.688 & 0.791 & 0.13 & 1 & 4.4 & 2.2 & $1 \times 10^{-4}$ & 6.0 & 0.2 \\
\hline
\end{tabular}

*The actual value of granular hardness, $\mathrm{h}_{\mathrm{s}}$, is $2300 \mathrm{MPa}$. This value is reduced by $10 \%$ due to low-stress soil state

Table 2 List of possible calculation methods of contact stiffness

\begin{tabular}{|c|c|c|}
\hline Description & Equation & $\begin{array}{l}\text { Eq. } \\
\text { No. }\end{array}$ \\
\hline The minimum mass of the slave and master part & $k_{c}=0.5 \times p f a c \times \frac{\min \left(m_{s}, m_{m}\right)}{\Delta t^{2}}$ & $(14)$ \\
\hline The maximum mass of the slave and master part & $k_{c}=0.5 \times p f a c \times \frac{\max \left(m_{s}, m_{m}\right)}{\Delta t^{2}}$ & $(15)$ \\
\hline $\begin{array}{l}\text { The geometric mean of the mass of the slave and } \\
\text { master part }\end{array}$ & $k_{c}=0.5 \times p f a c \times \frac{\sqrt{m_{s} \times m_{m}}}{\Delta t^{2}}$ & $(16)$ \\
\hline $\begin{array}{l}\text { Using the bulk modulus of the slave or Lagrangian } \\
\text { part }\end{array}$ & $k_{c}=0.5 \times p f a c \times K \times \sqrt{A} \times \frac{m_{s} \times m_{m}}{m_{s}+m_{f}}$ & $(17)$ \\
\hline Using a user-defined curve & (coupling pressure vs penetration) & - \\
\hline
\end{tabular}

Table 3 The first five eigenfrequencies obtained from the numerical eigenvalue analysis for three different models (the bold numbers indicate the frequency which showed a similar mode shape as in the experiment)

\begin{tabular}{|c|c|c|}
\hline Quarter 3D model & Half 3D model & Axisymmetric 2D model \\
\hline 13.65 & 13.95 & 13.84 \\
\hline $\mathbf{2 3 . 9 8}$ & 16.14 & $\mathbf{2 2 . 5 0}$ \\
\hline 28.94 & $\mathbf{2 0 . 7 7}$ & 34.50 \\
\hline 39.73 & 21.42 & 41.17 \\
\hline 41.20 & 25.24 & 43.67 \\
\hline
\end{tabular}

Table 4 Properties of the vibratory and impact loading as well as the calculated momentums corresponding to reaching the depth of $0.56 \mathrm{~m}$

\section{Momentum calculation of positive frequency load}




\begin{tabular}{|c|c|}
\hline Static load, $F_{S}(\mathrm{~N})$ & 419.3 \\
\hline Centrifugal force, $F_{d}(\mathrm{~N})$ & 1670 \\
\hline Time of applying the load (sec) & 11 \\
\hline Frequency $(\mathrm{Hz})$ & 23 \\
\hline Total Momentum (N.s) & 8339 \\
\hline \multicolumn{2}{|c|}{$\begin{array}{c}\text { Momentum calculation of positive Impact } \\
\text { load }\end{array}$} \\
\hline Impact duration (sec) & 0.01 \\
\hline Static load, $F_{S}(\mathrm{~N})$ & 661 \\
\hline Impact force, $F_{d}(\mathrm{~N})$ & 8135 \\
\hline Number of blows & 70 \\
\hline Total Momentum (N.s) & 10566 \\
\hline
\end{tabular}

\section{Figures}

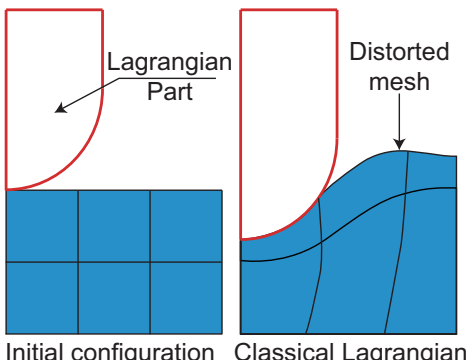

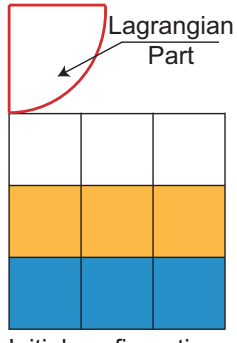

Initial configuration

Material A

Material B

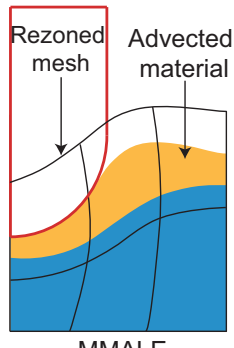

MMALE

Figure 1 Schematic diagram of MMALE approach compared to the classical Lagrangian FEM [17] 


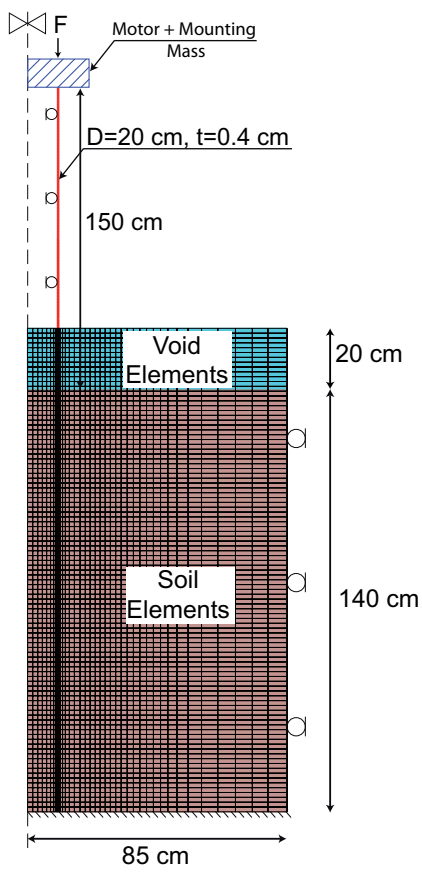

Figure 2 Numerical model configuration of the pile installation problem using impact and vibratory driving in the dense Berlin sand $\left(I_{D}=0.75\right)$ (axisymmetric boundary conditions are applied accordingly)

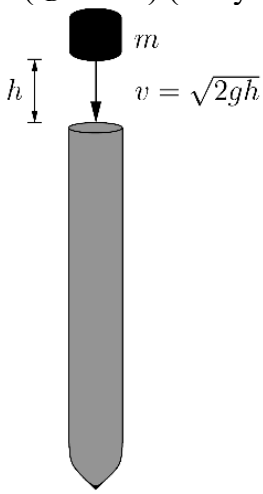

(a)

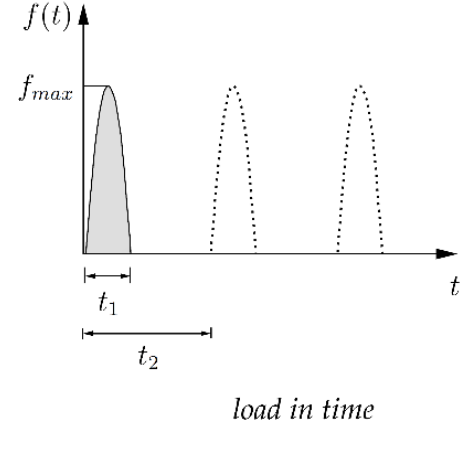

(b)

Figure 3 Schematic of the impact problem and the idealized load application history during the impact driving [32]

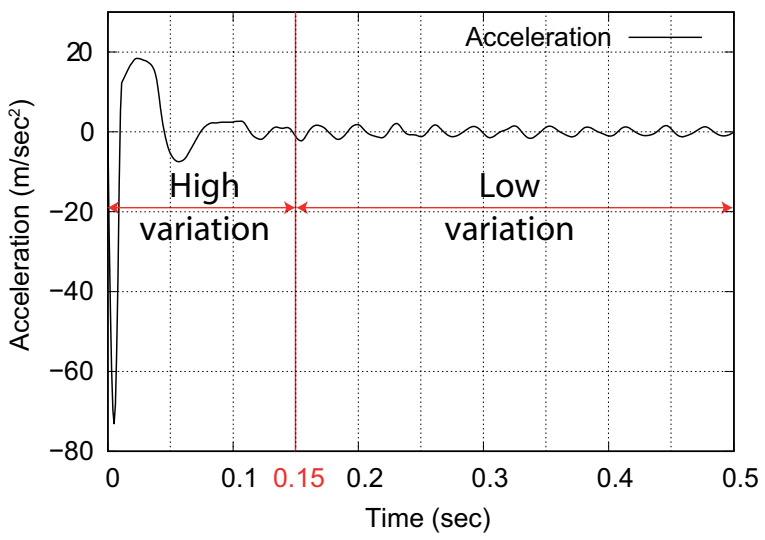

Figure 4 The acceleration history of the pile due to one blow in the case of impact driving 

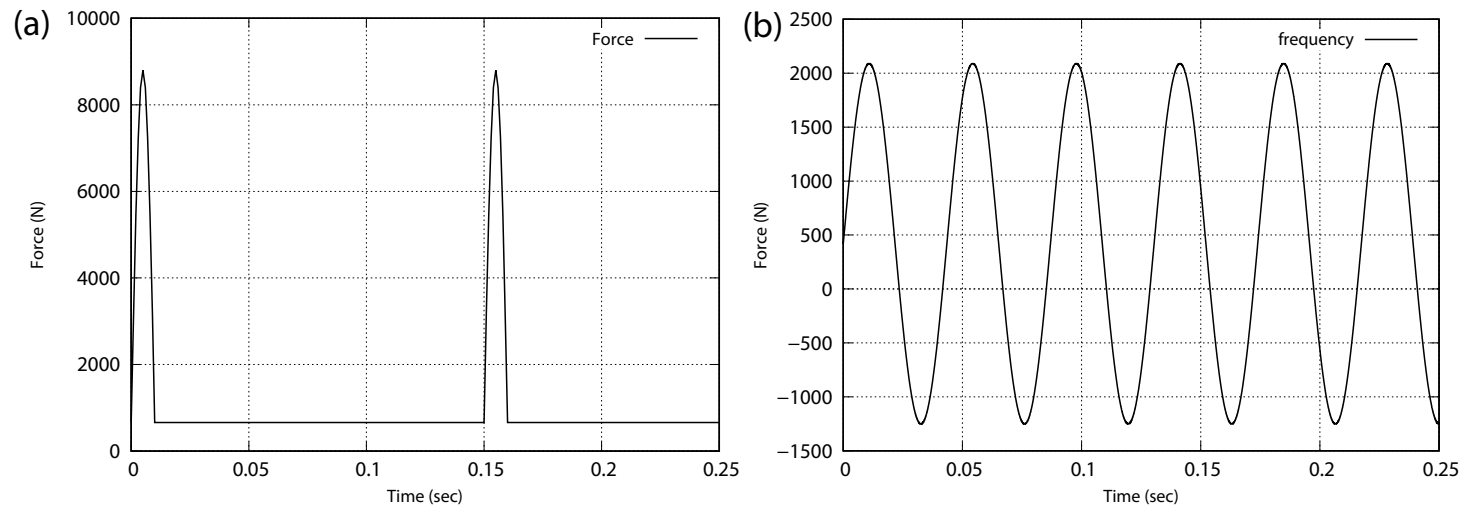

Figure 5 Load application curve of the impact (a) and vibratory (b) driving

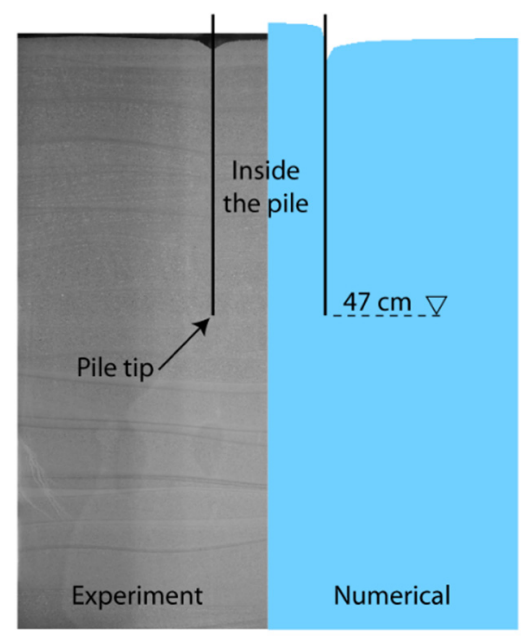

a) Impact driving

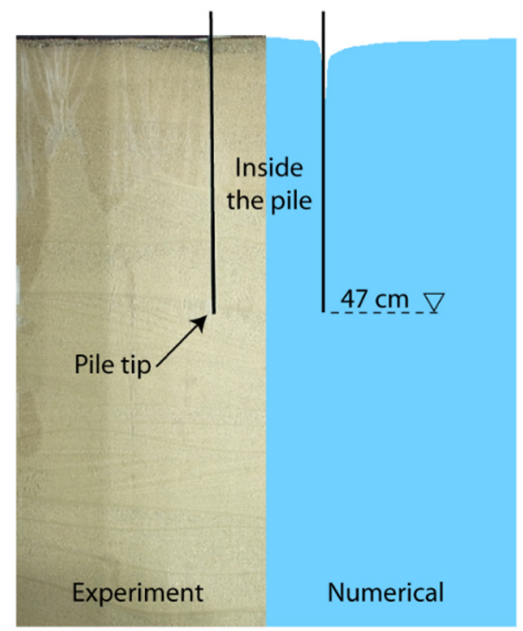

b) Vibratory driving

Figure 6 Comparison of the soil deformation from the numerical model and the experiment by impact (left) and vibratory driving (right) in the dense Berlin sand $\left(\mathrm{I}_{\mathrm{D}}=0.75\right)$ 

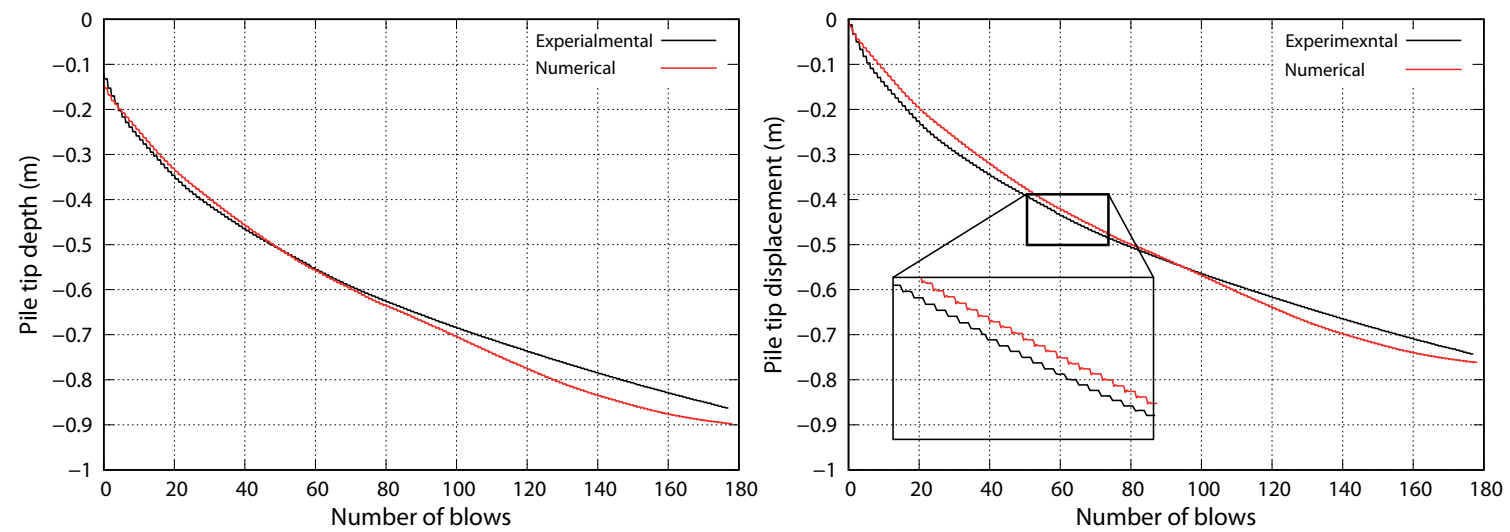

(a)
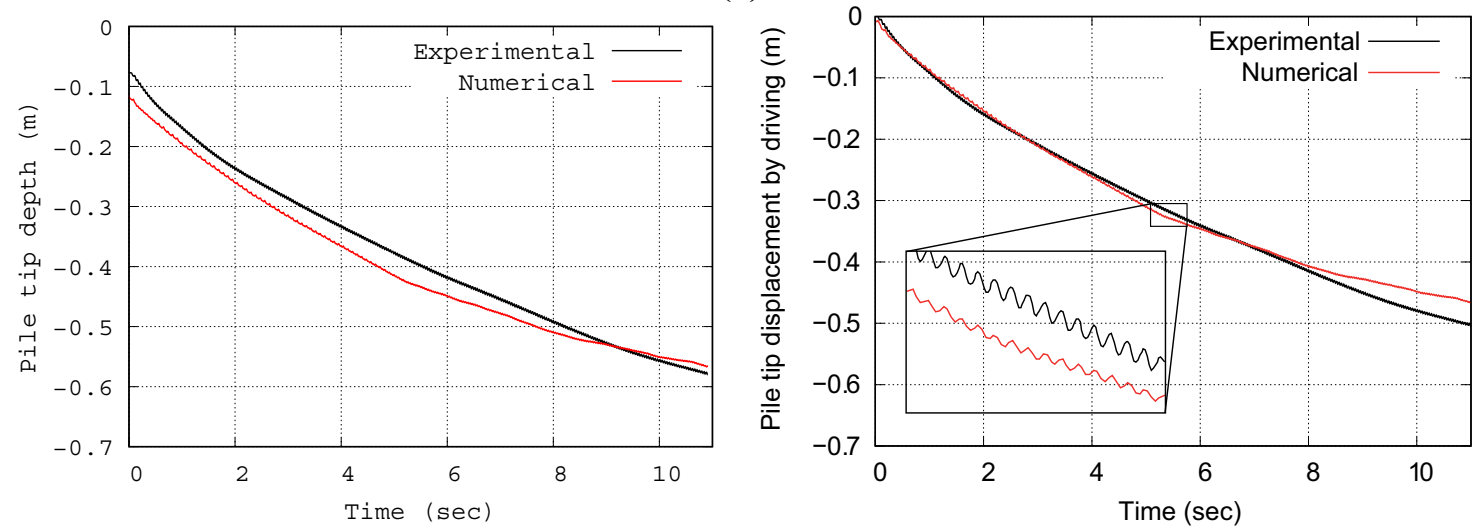

(b)

Figure 7 Pile tip depth and displacement curves from the numerical models and the experiments in the case of a) impact driving and $b$ ) vibratory driving in the dense Berlin sand
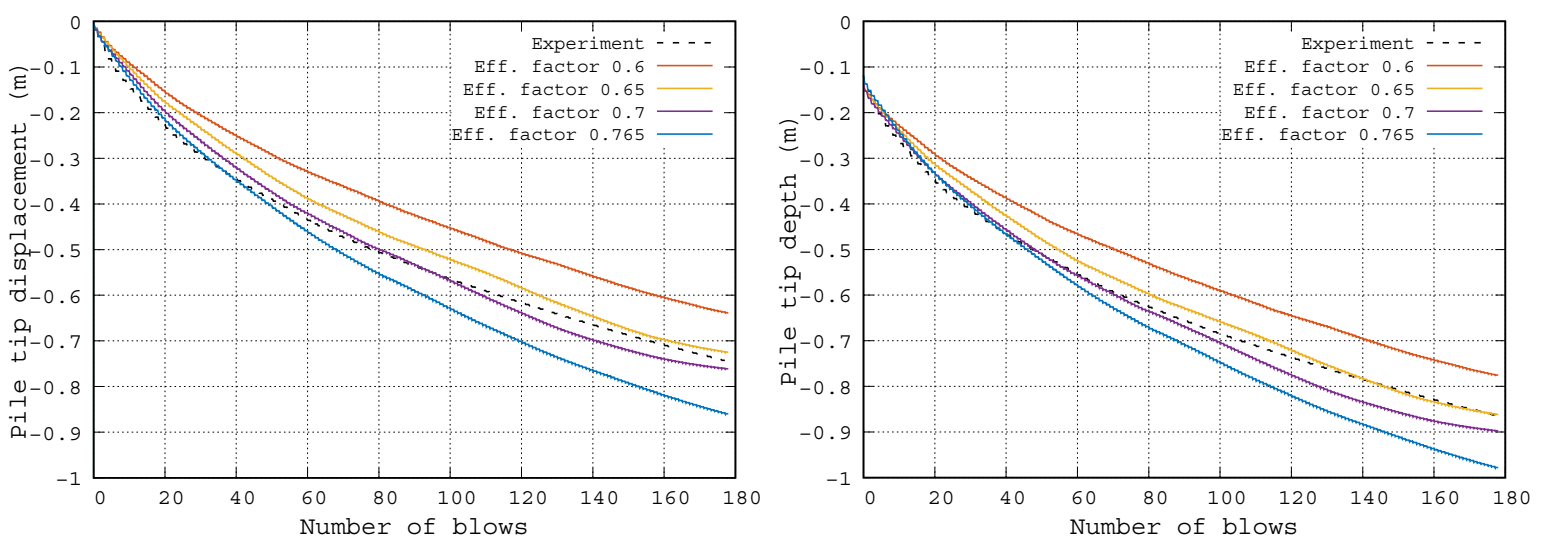

Figure 8 Comparison of penetration curves obtained with different efficiency factor in the case of impact driving in the dense Berlin sand 


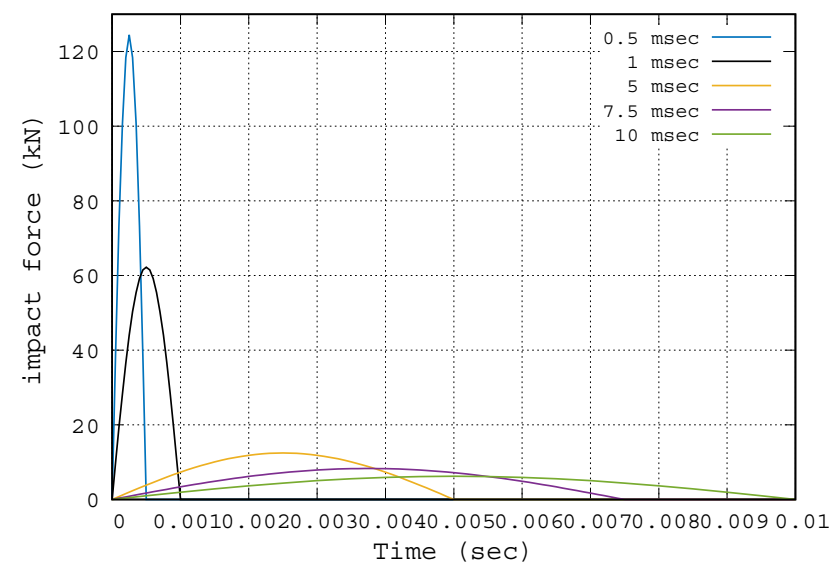

Figure 9 Load application history curves of one hammer blow for different impact cases where the impact duration, $t_{l}$, and the corresponding maximum force, $F_{\max }$, is changed (for the sake of brevity, the values of $t_{1}=15 \& 20 \mathrm{msec}$ are not shown)

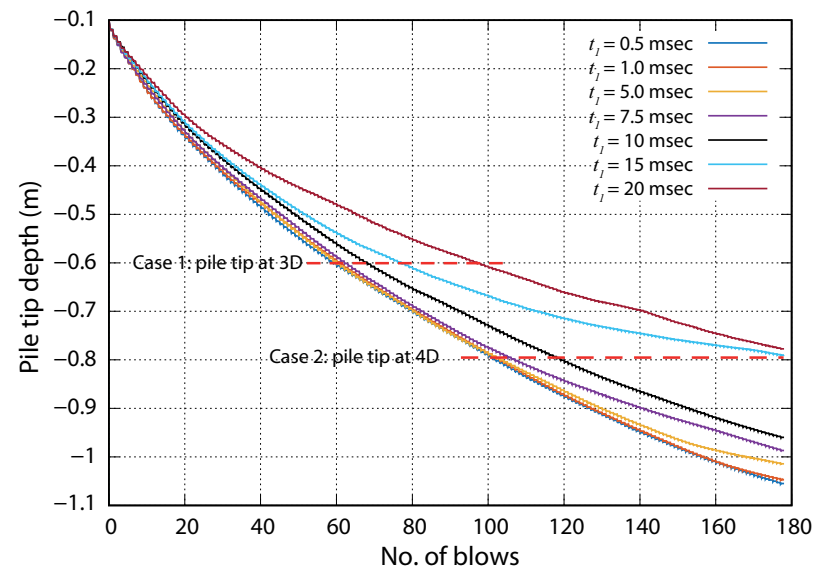

Figure 10 Comparison of the pile tip displacement curves obtained from different impact duration, $t_{l}$, in the case of impact driving in the dense Berlin sand $\left(I_{D}=0.75\right)$ 

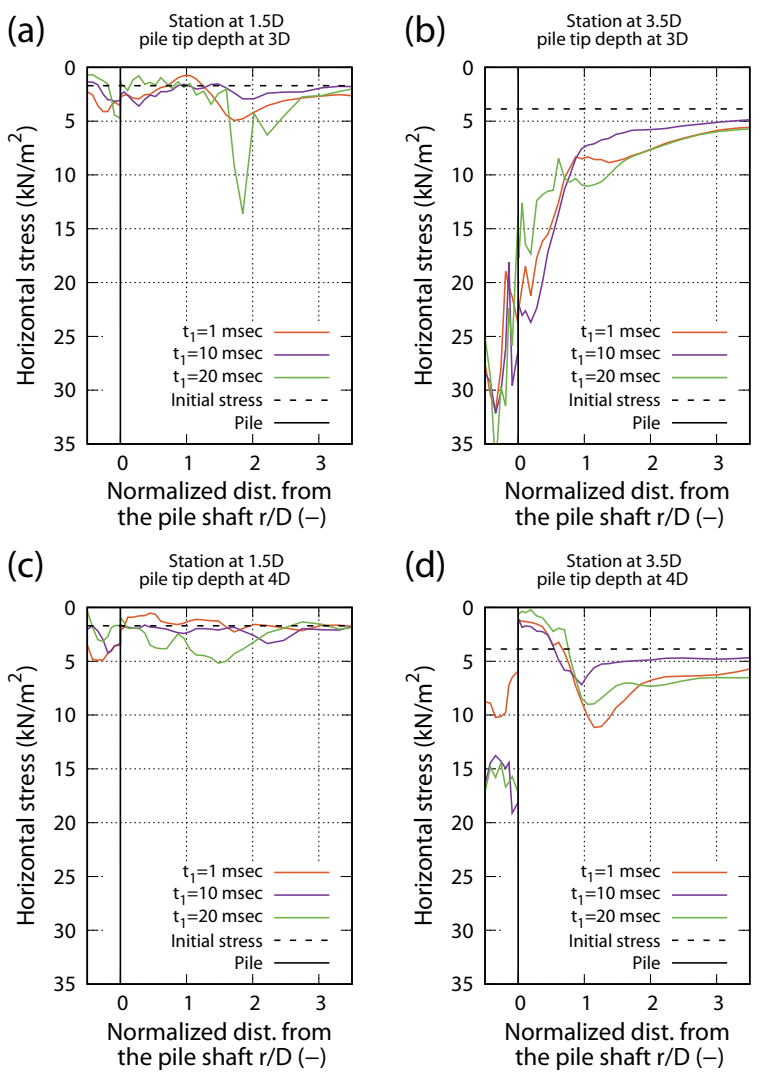

Figure 11 Comparison of the change in horizontal stress at pile tip depths of 3D and 4D at two stations with depth of $1 \mathrm{D}$ and $3 \mathrm{D}$ from the surface in the case of various impact duration of impact driving in the dense Berlin sand $\left(\mathrm{I}_{\mathrm{D}}=\right.$ 0.75 ); $\mathrm{D}$ is the pile diameter; $\mathrm{r}$ is the distance from the pile shaft 

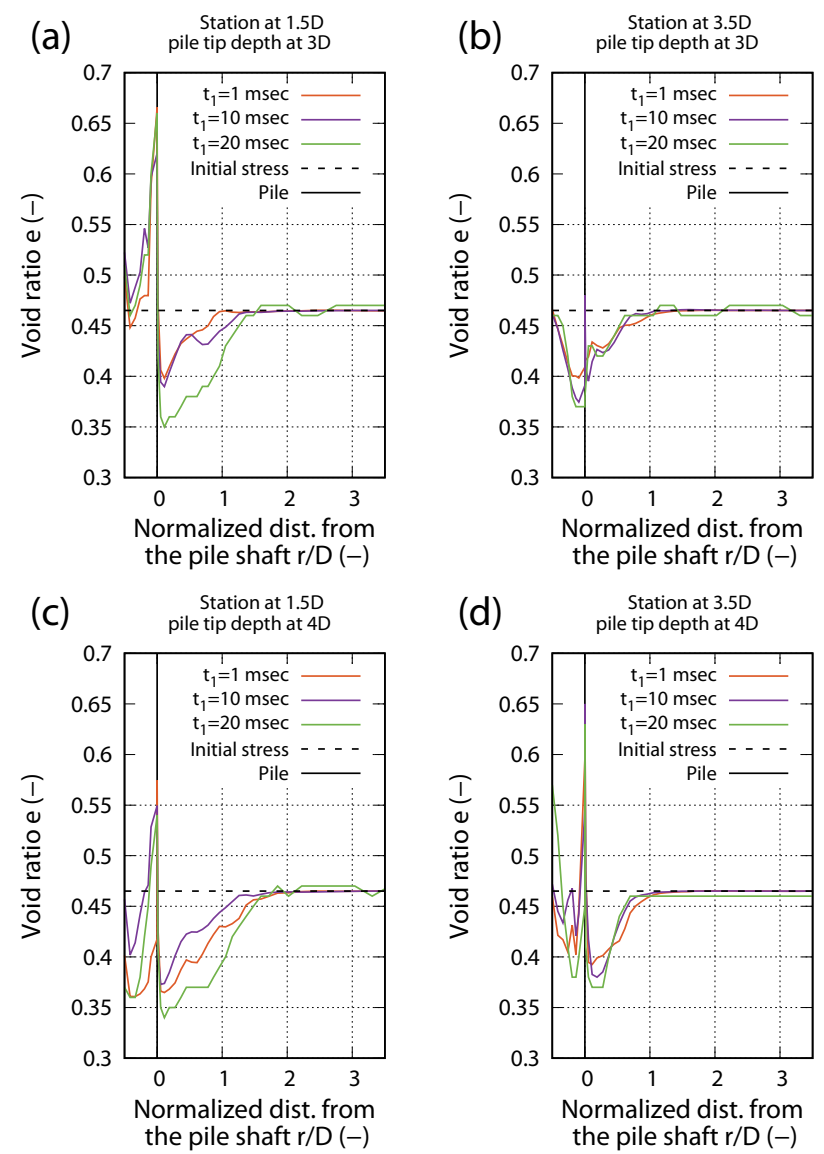

Figure 12 Comparison of the change in void ratio at pile tip depths of 3D and 4D at two stations with depth of 1D and $3 \mathrm{D}$ from the surface in the case of various impact duration of impact driving in the dense Berlin sand $\left(\mathrm{I}_{\mathrm{D}}=\right.$ 0.75 ); $\mathrm{D}$ is the pile diameter; $r$ is the distance from the pile shaft

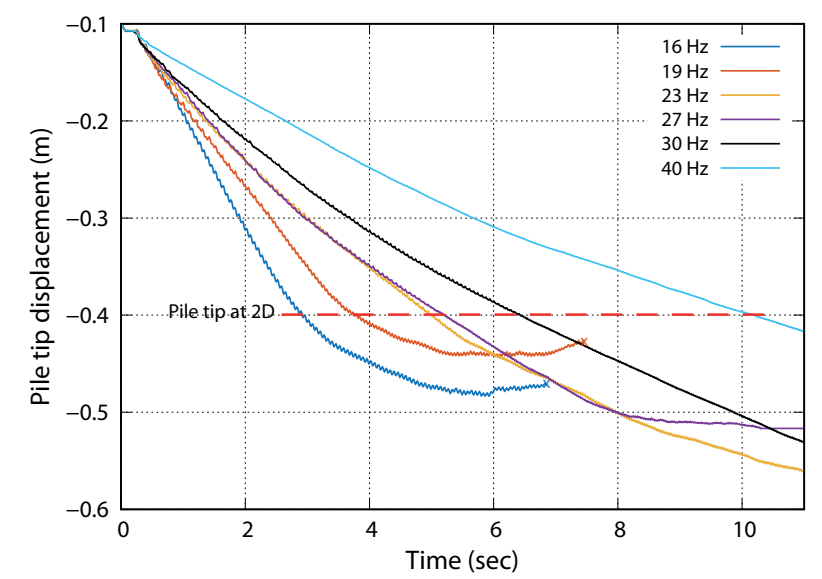

Figure 13 Comparison of the pile tip displacement curves obtained from different driving frequencies, $f$, in the case of vibratory driving in the dense Berlin sand $\left(I_{D}=0.75\right)$ 

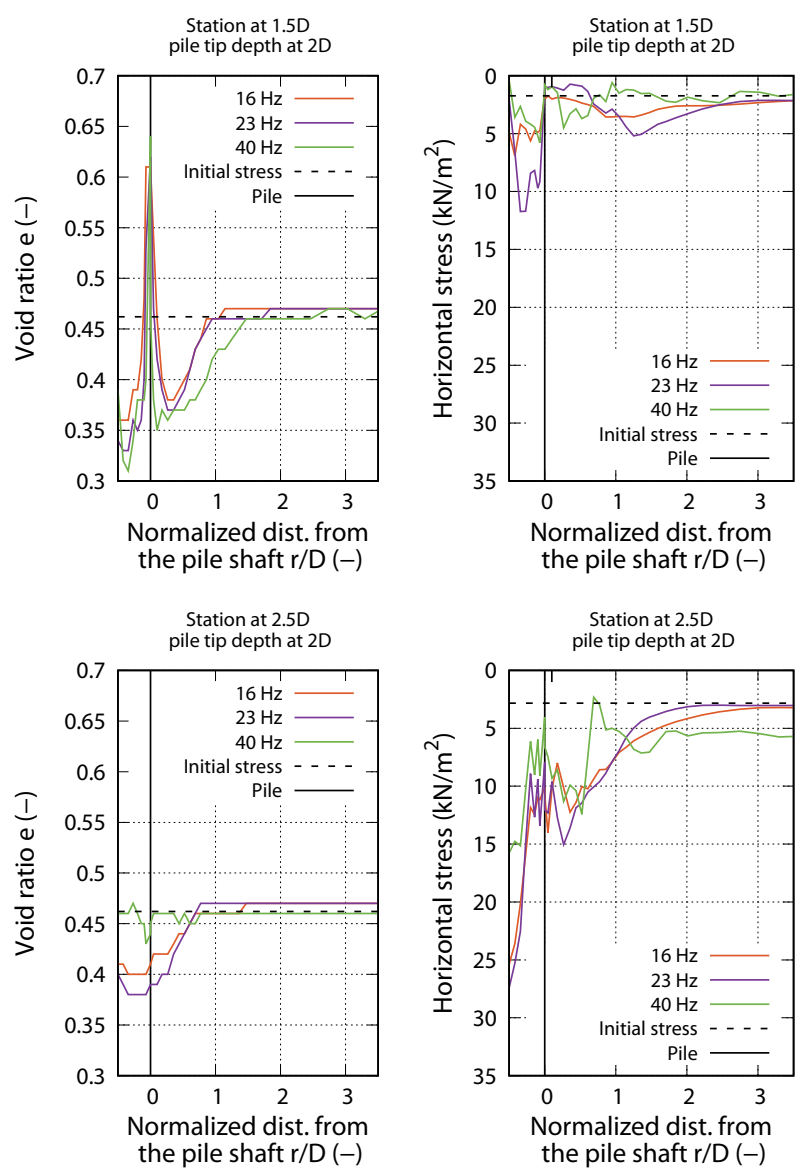

Figure 14 Void ratio and horizontal stress measured at two stations at the depths of $1.5 \mathrm{D}$ and $2.5 \mathrm{D}$ with the pile depth of 2D during the vibratory driving in the dense Berlin sand $\left(I_{D}=0.75\right)$ using three different frequencies $(D$ is the pile diameter)

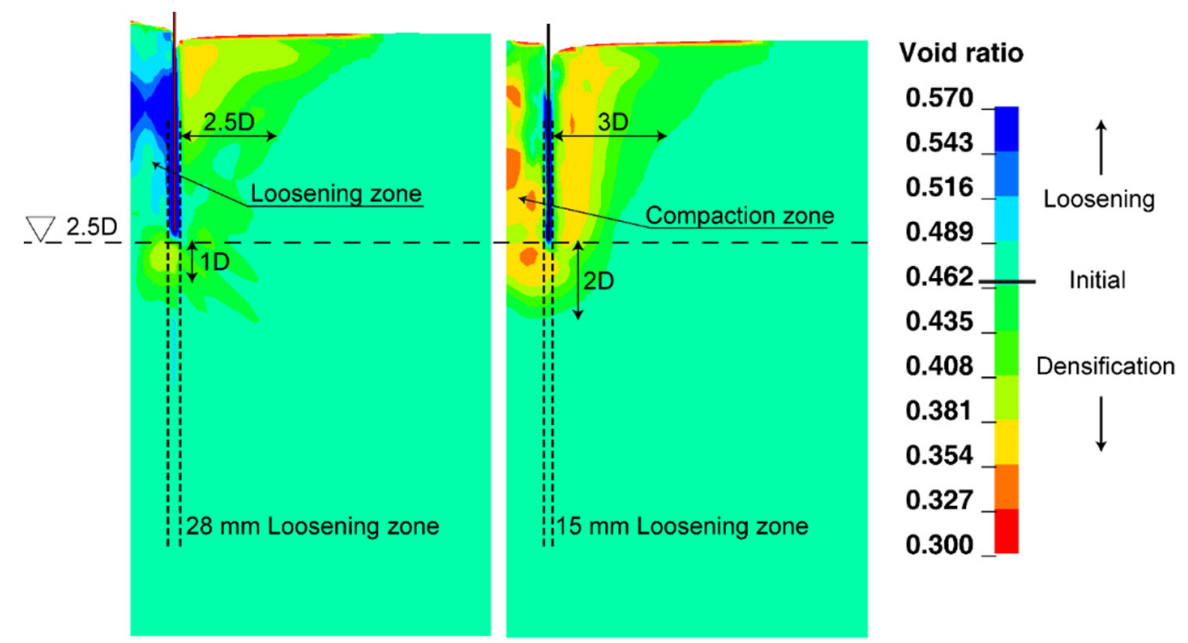

Figure 15 Void ratio distribution at the pile tip depth of 2.5D for the impact driving (left) and vibratory driving (right) in the dense Berlin sand $\left(I_{D}=0.75\right)$ (initial void ratio, $\left.e_{\text {initial }}=0.465\right)$ 


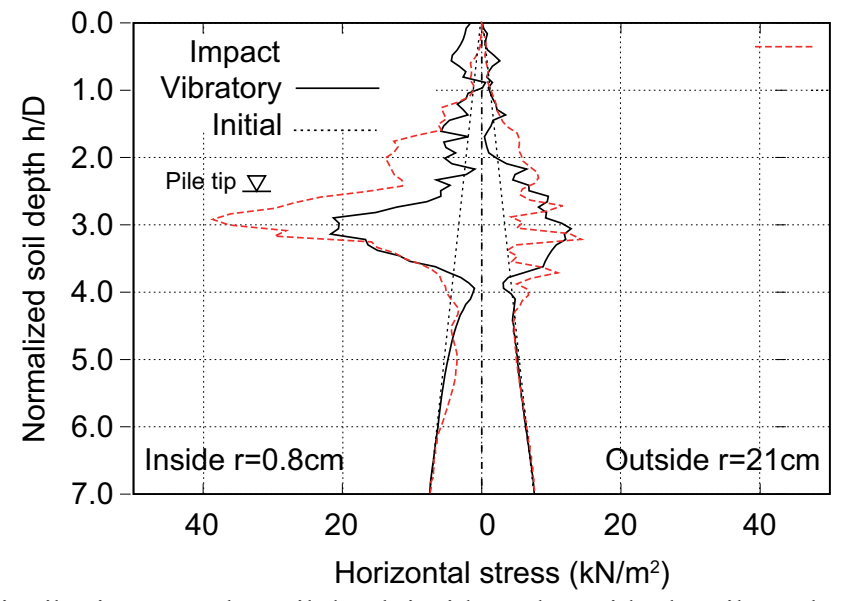

Figure 16 Horizontal stress distribution over the soil depth inside and outside the pile at the pile tip depth of 2.5D for the case of impact and vibratory driving in the dense Berlin sand $\left(\mathrm{I}_{\mathrm{D}}=0.75\right)$ (positive value indicates compression)

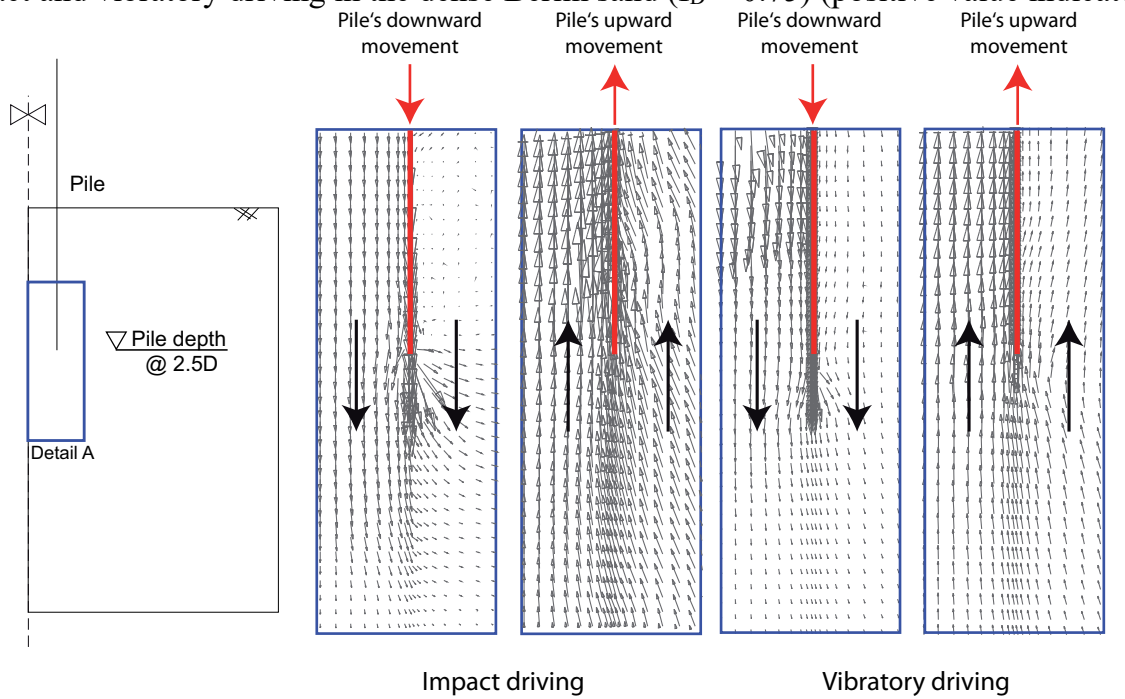

Figure 17 Velocity field of the soil regime around the pile tip during impact and vibratory driving. at pile's upward and downward movement
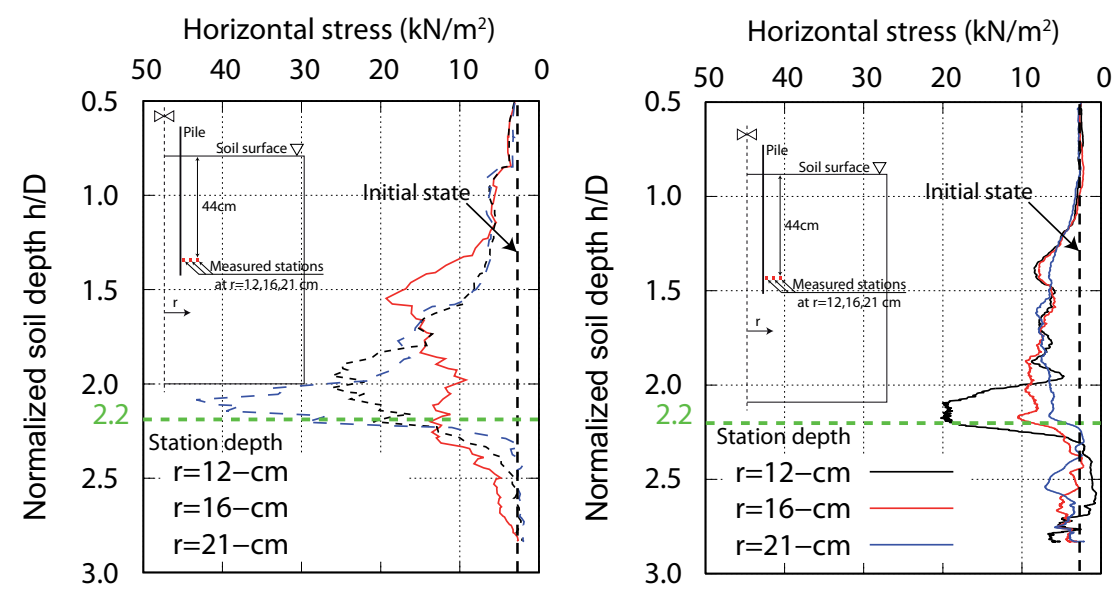

Figure 18 Horizontal stress history at three stations outside the pile, at the depth of $0.47 \mathrm{~m}$ during impact (left) and vibratory (right) driving in the dense Berlin sand $(\mathrm{ID}=0.75)$ (positive value indicates compression). Note: the pile 
was initially placed $10 \mathrm{~cm}$ wished-in before initiation of driving as mentioned in the text; $r$ is the distance from the axis of symmetry to the measuring stations
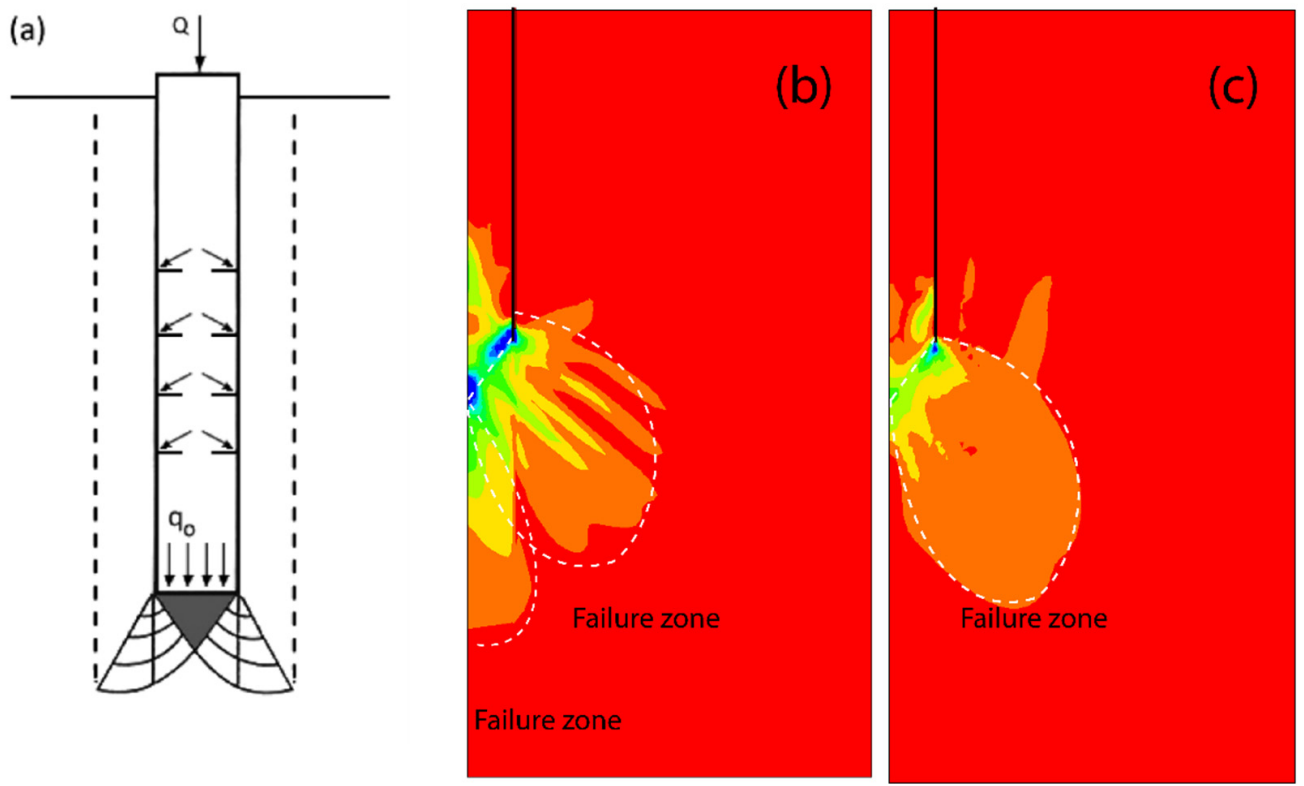

Max shear stress

(kPa)

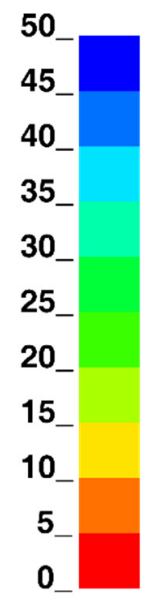

Figure 19 Schematic of the failure pattern around the closed pile tip developed by (a) Vesić [38], and the calculated maximum shear stress at the pile tip depth of $2.5 \mathrm{D}$ in the numerical model for the case of (b) impact and (c) vibratory driving in the dense Berlin sand $\left(\mathrm{I}_{\mathrm{D}}=0.75\right)$; $\mathrm{D}$ is the pile diameter

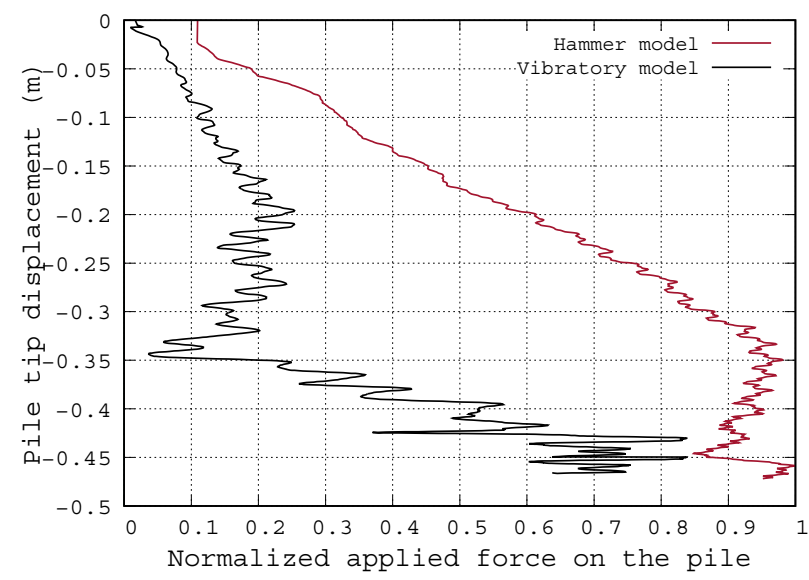

Figure 20 Comparison of the applied force on the pile during pile displacement for cases of impact and vibratory driving in the dense Berlin sand (ID $=0.75$ ); the applied forces are normalized against the maximum applied force during impact driving 